\title{
Concept for Sustained Plant Production on ISS Using VEGGIE Capillary Mat Rooting System
}

\author{
Gary W. Stutte ${ }^{1}$ and Gerard Newsham. ${ }^{2}$ \\ ESC-Team QNA, Kennedy Space Center, FL 32899 \\ Robert M. Morrow ${ }^{3}$ \\ Orbitec, Madison, WI 53717 \\ and \\ Raymond M. Wheeler ${ }^{4}$ \\ NASA, Kennedy Space Center, FL 32899
}

\begin{abstract}
Plant growth in microgravity presents unique challenges associated with maintaining appropriate conditions for seed germination, seedling establishment, maturation and harvest. They include maintaining appropriate soil moisture content, nutrient balance, atmospheric mixing and containment. Sustained production imposes additional challenges of harvesting, replanting, and safety. The VEGGIE is a deployable (collapsible) plant growth chamber developed as part of a NASA SBIR Phase II by Orbitec, Madison, WI. The intent of VEGGIE is to provide a low-resource system to produce fresh vegetables for the crew on long duration missions. The VEGGIE uses and LED array for lighting, an expandable bellows for containment, and a capillary matting system for nutrient and water delivery. The project evaluated a number of approaches to achieve sustained production, and repeated plantings, using the capillary rooting system. A number of different root media, seed containment, and nutrient delivery systems were evaluated and effects on seed germination and growth were evaluated. A number of issues limiting sustained production, such as accumulation of nutrients, uniform water, elevated vapor pressure deficit, and media containment were identified. A concept using pre-planted rooting packs shown to effectively address a number of those issues and is a promising approach for future development as a planting system for microgravity conditions. (Supported by NASA IPP Grant).
\end{abstract}

\section{Nomenclature}

$\begin{array}{ll}\text { VEGGIE } & =\text { Vegetable Production Unit } \\ \text { LED } & =\text { Light Emitting Diode } \\ \text { SBIR } & =\text { Small Business Innovative Research } \\ \text { IPP } & =\text { Innovative Partnership Program } \\ \text { CTB } & =\text { Crew Transfer Bag } \\ \text { EC } & =\text { Electrical Conductivity } \\ \text { CEC } & =\text { Controlled Environment Chamber } \\ \text { PAR } & =\text { Photosynthetically Active Radiation } \\ \text { FM } & =\text { Fresh Mass } \\ \text { DM } & =\text { Dry Mass } \\ \text { LAI } & =\text { Leaf Area Index }\end{array}$

\footnotetext{
${ }^{1}$ Senior Scientist, Space Life Science Laboratory, Mail Code ESC-53.

${ }^{2}$ Scientist I, Space Life Science Laboratory, Mail Code ESC-53

${ }^{3}$ Senior Scientist

${ }^{4}$ Surface Systems Lead, Mail Code NE-S-1 


$\begin{array}{ll}\text { SLM } & =\text { Specific Leaf Mass } \\ \text { SPAD } & =\text { arbitrary unit of chlorophyll concentration from a commercial chlorophyll meter } \\ \text { ORAC } & =\text { Oxygen Radical Absorbance Capacity } \\ \text { TE } & =\text { Trolox Equivalent } \\ \text { DI } & =\text { Deionized water } \\ \text { VPD } & =\text { Vapor Pressure Deficit } \\ \text { BPSe } & =\text { Biomass Production System for Education } \\ \text { RW } & =\text { Rockwool } \\ \text { ICP } & =\text { Inductively coupled plasma spectrometry } \\ \text { IC } & =\text { Ion chromatography } \\ \text { QD } & =\text { Quick Disconnect }\end{array}$

\section{Introduction}

Fresh vegetables and fruits can add flavors, textures, and bio-available nutrients to the diet of astronauts and improve the quality of life for long missions (Lane and Schoeller, 2000). Yet, the shelf life of these fresh foods is limited and to date they have only been provided through stowage. Further, the bioprotective qualities of fruits and vegetables decline quickly when stored under spaceflight temperature and radiation environments. An alternative to complete reliance on stored food is to grow vegetables in situ to supplement the crew's diet. This concept has been discussed for nearly 20 years (Kliss and MacElroy, 1990; Kliss et al., 2000; Morrow et al., 2005) and represents the first logical step in a sequence to developing food production technologies for Lunar Surface Systems and more extensive bioregenerative capabilities for Mars missions (Wheeler et al., 2001). The Russian space program currently has a plant test chamber on ISS called "Lada", but is limited in its size $\left(0.034 \mathrm{~m}^{2}\right)$ and range of species it can accommodate (Sytchev et al., 2007), and uses mercury-containing fluorescent lamps.

The VEGGIE plant chambers were built by Orbitec as part of a NASA Phase II SBIR grant and consist of a rooting base, an expandable clear bellows enclosure, and an LED light cap (Fig. 1). The chambers can be collapsed to stow multiple units in a single mid-deck locker or cargo transfer bag (CTB). Like Lada, the VEGGIE chambers would use cabin air for thermal control and $\mathrm{CO}_{2}$ supply. However unlike Lada, lighting is provided with solid state LEDs. In addition, each VEGGIE unit would provide $0.17 \mathrm{~m}^{2}$ of growing area--5 times that of Lada.

Three high fidelity VEGGIE systems developed as part of the Phase II SBIR have been tested — one at Orbitec and two at KSC. The VEGGIE unit at Orbitec has been used to demonstrate feasibility for both ISS (Morrow et al., 2005) and Lunar applications (Morrow and Remiker, 2009). The two VEGGIE units at KSC were used to demonstrate the feasibility of using the VEGGIE production concept for production of salad crops on the Lunar surface though the 2009 KSC CDDF Project, "Defining sustained salad crop production requirements for Lunar Surface". Based on the results from the 2009 KSC CDDF project and recent advances in solid state lighting, a number of improvements were identified to enhance the capabilities of a second generation VEGGIE (Fig. 1) to improve the quantity and quality of salad crops produced with a significant reduction in power demand.

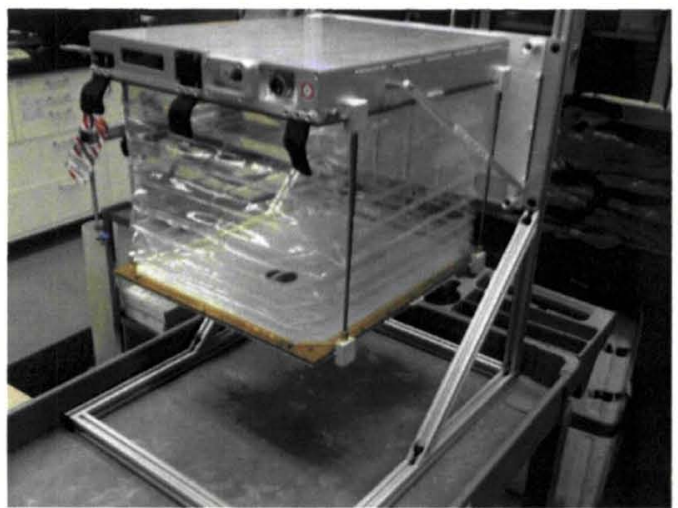

Figure 1. $2^{\text {nd }}$ Generation VEGGIE LED array and bellows assembly as delivered to Space Life Science Laboratory on 7 May, 2010. 
This project had the objective of developing planting, harvesting and operational protocols that would be suitable for operation of a VEGGIE plant growth system on the International Space Station (ISS). The components of this project are discussed in the report:

1. Experiments conducted to develop a concept of operations for growing salad crops on ISS using VEGGIE

2. Evaluation of plant growth with the "Rooting Pillow" concept of Operations using the 2nd Generation VEGGIE light cap.

3. Refinement of "Rooting Pillow" into an ISS prototype design

\section{Concept of Operations}

The VEGGIE root mat consists of a Nomex wicking surface that protrudes from a sealed reservoir. The wick and reservoir are housed in a Teflon envelope with a separate top sheet that tucks or inserts into the edges of the envelope. The sealed reservoir can be filled with $\sim 1.5 \mathrm{~L}$ of solution through a quick disconnect (QD) fitting.

In developing a concept of operations, the following three tenants were assumed:

1. The basic concept of VEGGIE root mat would be retained.

2. The planting and growth operations can be implemented in a microgravity environment.

3. The planting and growth procedures should support multiple cropping systems.

The basic concept of operation of the VEGGIE rooting mat is of passive delivery of water and nutrients from the reservoir based on plant demand. This demand is driven by evapotranspiration, which draws water through the wicking interface and into the planting media. The surface tension of water to the wicking material prevents the accumulation of free water in microgravity and provides for a contained means of moving water across a barrier.

A number of experiments were performed to test concepts that would support plant growth in microgravity with a minimum of crew input. The approach, rational, implementation, and outcomes of these experiments are presented below.

\section{A. Planting lettuce seed directly on Nitex wicking material}

The objective of this test was to determine whether lettuce can be grown directly on wicking material without a rooting matrix. Nitex is a hydrophyllic nylon material that has been used as wicking material for many years in hydroponic systems at Kennedy Space Center, FL, and has a fine weave that minimizes root growth through the fabric. It was hypothesized that plants could be grown directly on the root mats, as with a hydroponic system, and eliminates the need for a rooting matrix to support crops. This approach would have the advantage of minimal crew input, minimal stowage volume, and ease of deployment.

Either a single or double sheet of Nitex was cut to size in order to cover the Nomex surface on the VEGGIE rooting mat. The Nitex sheet was covered with an opaque sheet prepared from black/white greenhouse plastic, and with holes cut out for the seeds. In the single Nitex sheet treatment, seeds of lettuce cvs. Flandria, Outredgeous, and Firecracker were placed directly on the Nitex wicking material. On the double Nitex sheet treatment, the seeds were placed between the folds through a slit in the upper Nitex layer. The VEGGIE Rooting mat reservoir was filled with $\sim 1.5 \mathrm{~L}$ of full strength Hoagland nutrient solution (EC or electrical conductivity of $2400 \mu \mathrm{S} \mathrm{cm}^{-1}$ ).

The rooting mats were then placed under $1^{\text {st }}$ Generation VEGGIE units \#1 or \#2 in the flight-like configuration (bellows in place) and grown for 21-28 days in the Space Life Sciences Lab controlled environment chamber (CEC) number 3. CEC 3 environmental setpoints were maintained at $23^{\circ} \mathrm{C}, 50 \% \mathrm{RH}$, and $1200 \mu \mathrm{mol} \mathrm{mol}^{-1} \mathrm{CO}_{2}$. Lettuce was grown under continuous (i.e., a 24-h light photoperiod) at $\sim 280 \mu \mathrm{mol} \mathrm{m}^{-2} \mathrm{~s}^{-1}$ PAR.

Results: Initial seed germination and seedling emergence was higher on the single layer Nitex treatment than the double layer Nitex treatment. Initial growth was higher on the single Nitex layer as well. After 14 days, there was 
noticeable stunting of growth in both treatments, and by 21 days after planting (DAP) rapid decline in all cultivars, resulting in very erratic growth (Fig. 2).

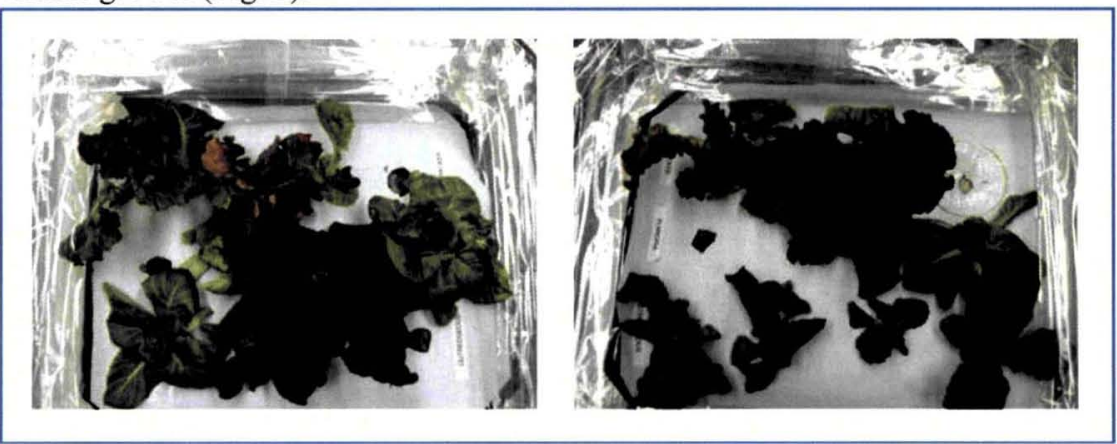

Figure 2: Lettuce growth at 21 DAP of seeds planted directly on a single layer of Nitex (Left) or between two Nitex layers (Right) and grown on full strength Hoaglands nutrient solution.

Inspection of the lettuce plants that were in decline revealed girdling or collapse of the stem at the interface between the stem and Nitex wick. This was observed in both the single and double layer Nitex treatments and with all three lettuce cultivars (Fig 3). This result is consistent with that observed with nutrient toxicity and water logging.

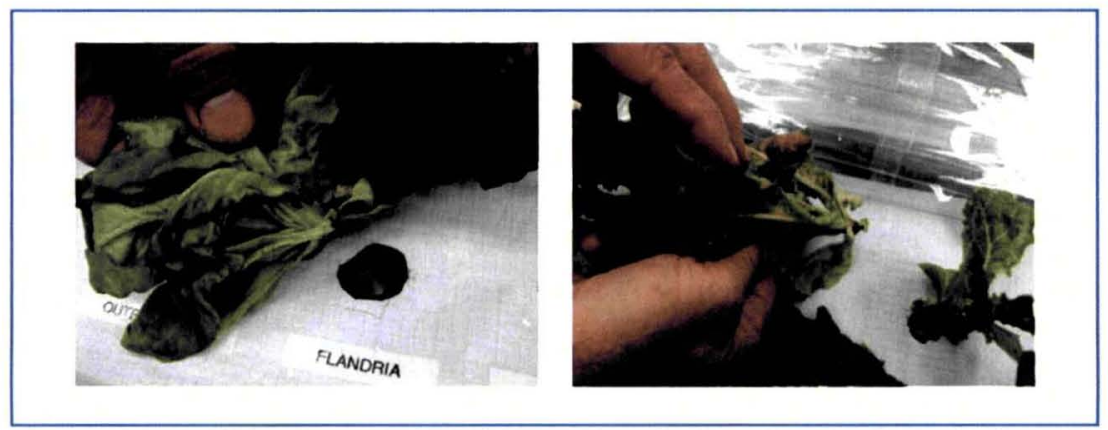

Figure 3: Girdling (collapse) of the stem at the Nitex surface for Flandria (Left) and Firecracker (Right) grown directly on Nitex using full strength Hoagland nutrient solution.

Inspection of the root system revealed excessive branching, discoloration, and thickening of the primary root that is consistent with salt damage. In addition, the roots of plants grown between the double Nitex layer treatment had fewer branches, and tip die-back that are symptomatic of waterlogging (Fig 4). However, due to the experiment configuration it was not possible to collect and analyze samples to confirm the visual diagnosis.

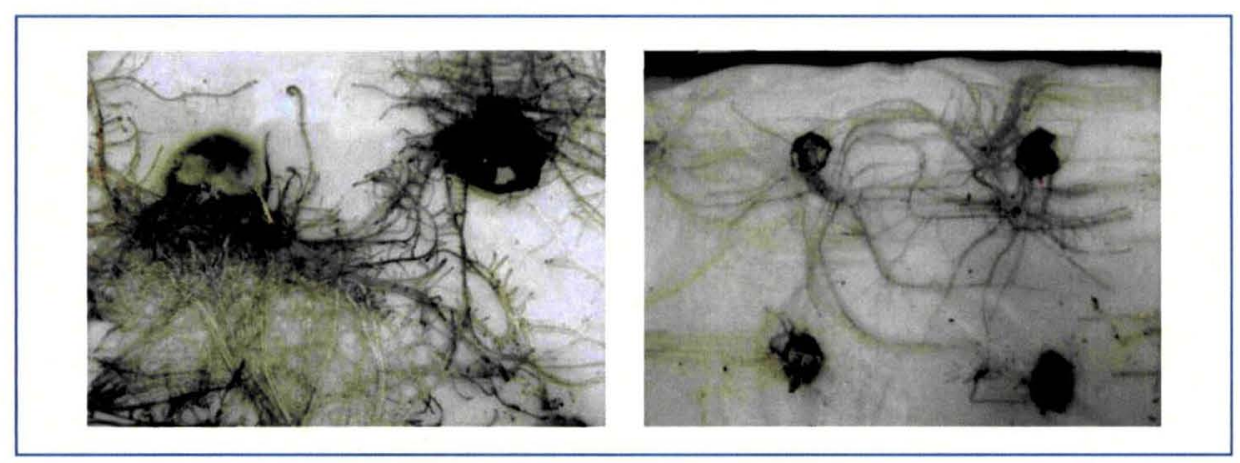

Figure 4: Root necrosis, excessive branching, and tip burn were observed on roots grown directly on a single layer of Nitex (Left). Root growth was stunted and less vigorous when grown between two layers of Nitex (Right).

There was no growth of roots through the Nitex barrier, which resulted in a very easy, straight-forward harvest of the root mat (Fig 5). 


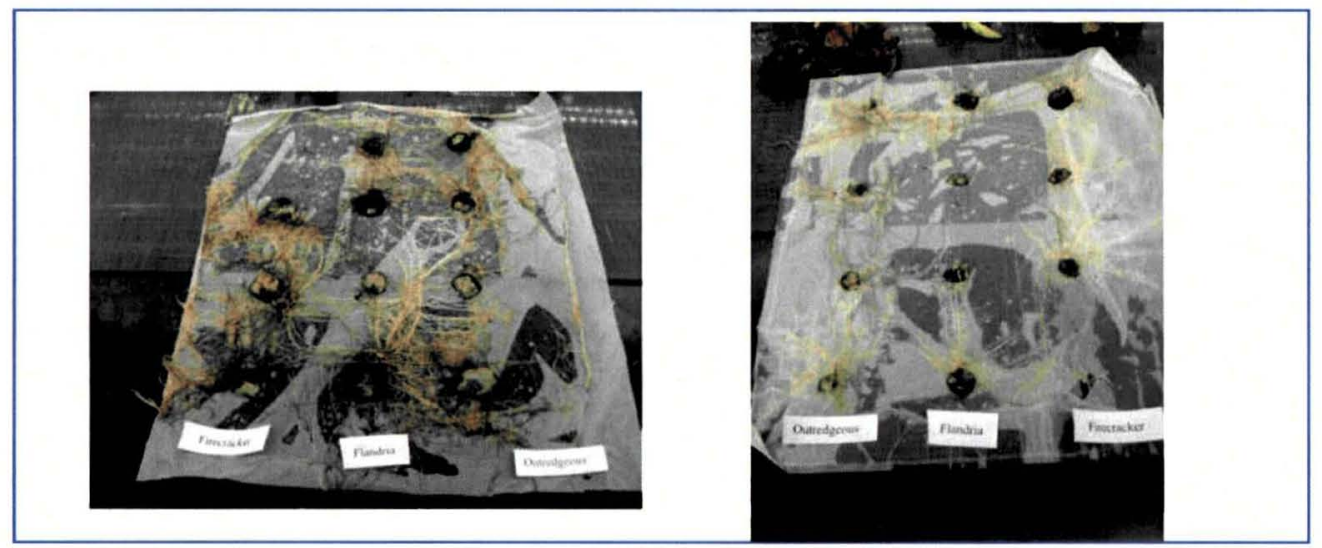

Figure 5: Both the single (Left) and double (Right) Nitex configurations contained the roots.

This experiment indicated that Nitex is an effective barrier between the root system and the Nomex wicking material of the VEGGIE rooting mat. Its hydrophilic properties allowed the transfer of water and nutrients while containing the root mat. Germination was good in both treatments, but emergence of several seedlings of the double Nitex layer configuration was delayed because they grew between the two sheets of Nitex. This will be a significant problem in the absence of a gravitational vector for orientation under spaceflight conditions. The early growth on a single layer of Nitex was encouraging, but the rapid decline due to apparent salt accumulation limits the utilization of this approach, and further development was discontinued.

\section{B. Planting in Rockwool and Oasis starter blocks using full strength Hoaglands nutrient solution.}

The objective of this test was to determine if seedling development and plant growth could be achieved using a solid rooting media. The planting system used by Orbitec involved planting rooting plugs directly on the mat and securing with a light-tight barrier [Deployable Vegetable Production System (VEGGIE) Operations Manual, OTC Document 272219, November, 2007].

Two media previously used to support plant growth during spaceflight experiments (Rockwool and Oasis foam) were evaluated as a rooting media. Two cm cubes of Rockwool and plugs $2 \mathrm{~cm}$ diameter of Oasis foam were used. The plugs were glued to the Nitex fabric using $2 \%$ Gum guar, an adhesive that has been used extensively for seed attachment during spaceflight (Fig 6). Three lettuce cultivars, Flandria, Outredgeous, and Firecracker were evaluated in this test.

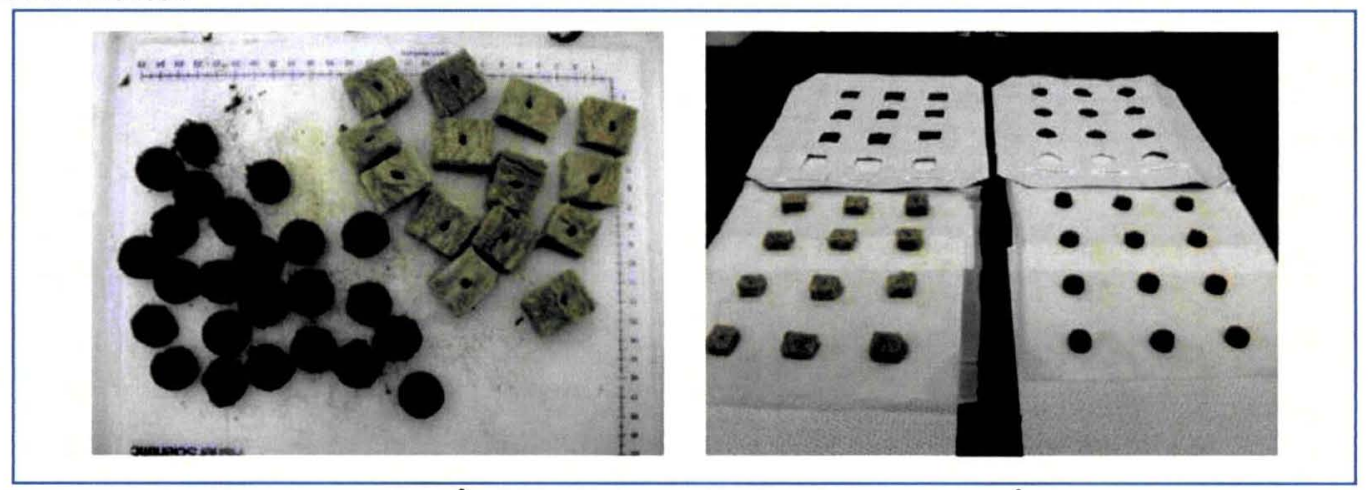

Figure 6 Left: Oasis foam plugs $\left(6.3 \mathrm{~cm}^{3}\right)$ (lower left) and Rockwool cubes $\left(8 \mathrm{~cm}^{3}\right)$ (upper right) were prepared for attachment to the Nitex sheet. Right. Rockwool cubes (Left) and Oasis plugs (Right) attached to the wicking material with opaque covering in the back.

The rooting blocks were each planted with 2 seeds of either the red-leaf lettuce varieties Outredgeous or Firecracker, or the green-bibb leaf cultivar Flandria, and placed on the VEGGIE rooting mat as shown below (Fig 7). 


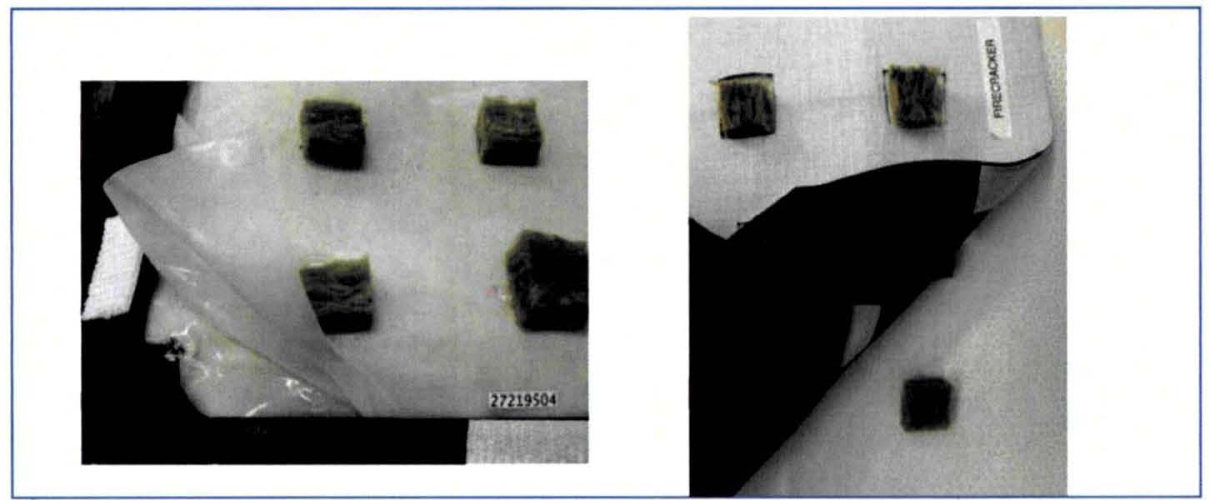

Figure 7: Rockwool cubes glued to the single sheet of Nitex wicking material with $2 \%$ gum guar were placed on the wicking surface of the VEGGIE rooting mat. The edges of the hydrophilic Nitex material are secured by tucking them under the Teflon flap of the rooting mat. Contact with the Nomex wicking surface is maintained by surface tension of the wet surfaces.( Left) An opaque barrier with sections cut out for the rooting blocks is placed over the Nitex to reduce evaporation and minimize algae growth (Right).

The root mat reservoir was filled with $\sim 1.5 \mathrm{~L}$ of $1 \mathrm{X}$ Hoagland's solution $\left(\mathrm{EC}=2400 \mu \mathrm{S} \mathrm{cm} \mathrm{cm}^{-1}\right.$ ) placed within the transparent bellows, and then placed under the $1^{\text {st }}$ Generation VEGGIE LED light array. The lighting was set to 280 $\mu \mathrm{mol} \mathrm{m} \mathrm{m}^{-2} \mathrm{~s}^{-1}$ PAR, the highest that could be achieved without exceeding the 4 amp limit of the LED array (Fig 8). CEC 3 environmental conditions were maintained as before.

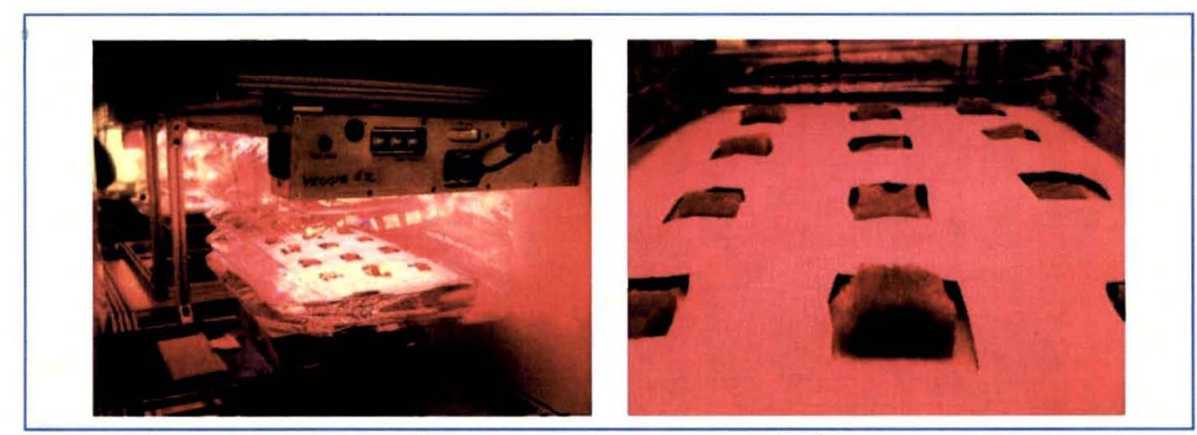

Figure 8 VEGGIE root mat configured in transparent bellows under $1^{\text {st }}$ Generation VEGGIE LED array (Left_. Close-up of planted Rockwool block on VEGGIE root mat (Right).

Germination was very poor at 7 days after planting (DAP) for all three cultivars planted in both the Oasis foam plugs and Rockwool cubes (Fig 9).

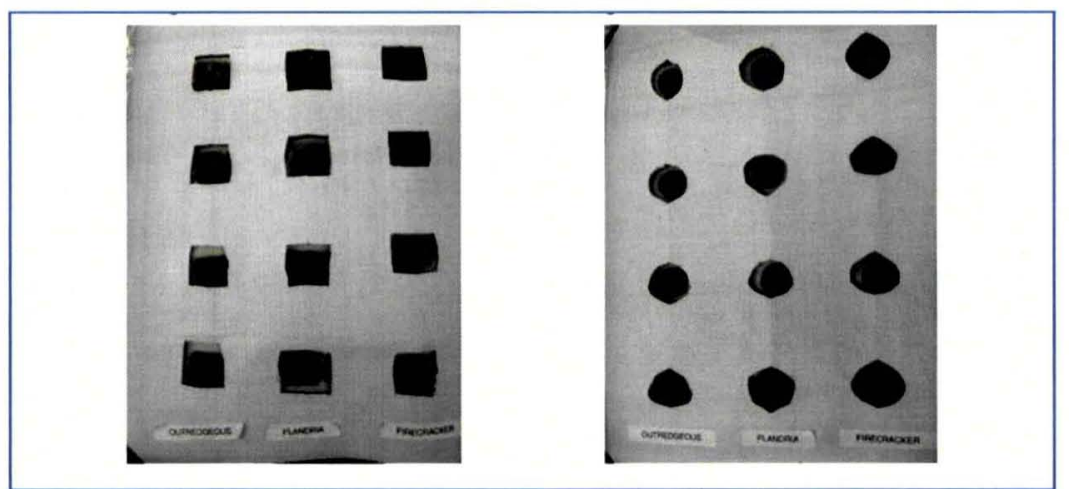

Figure 9: Germination of Outredgeous, Flandria, and Firecracker cultivars started in Rockwool (Left) or Oasis (Right) using full strength Hoagland's nutrient solution.

6

American Institute of Aeronautics and Astronautics 
Poor germination and failure to thrive was mostly like due to excessive salinity as evident by the appearance of salt crystals forming on the tips of the Rockwool fibers. The experiment was terminated, and several changes were implemented to mitigate the horticultural and environmental factors that would contribute to high salt concentrations.

\section{Planting in Rockwool and Oasis starter blocks using $1 / 2$ strength Hoagland solution.}

The objective of this test was to determine if reducing nutrient concentration in the VEGGIE nutrient reservoir thereby reducing salt accumulation would allow seed germination to occur. Several environmental factors can contribute to the development of salinity stress. These include nutrient concentration and evapotranspiration rate. Methodology changes were implemented to reduce the nutrient concentration and evapotranspirative demand during early seed development.

Rockwool cubes and Oasis plugs were cut to size as described above, then rinsed several times in deionized (DI) water to remove any residual nutrients or phytotoxic compounds from the media and off-gassed at $70^{\circ} \mathrm{C}$ in forced air oven for 16 hours prior to planting to remove phytotoxic volatiles. The rooting blocks were then attached to Nitex wicks with $2 \%$ gum guar, and planted as described above.

The VEGGIE nutrient reservoir was filled with $\sim 1.5 \mathrm{~L}$ of $1 / 2$ strength Hoagland solution $\left(\mathrm{EC}-1200 \mu \mathrm{S} \mathrm{cm}^{-1}\right)$ to reduce the overall nutrient salt concentrations, and placed under the $1^{\text {st }}$ Generation VEGGIE LED arrays as described above on 18 March 2010. The LEDs were kept OFF for the $1^{\text {st }}$ five days, in order to reduce the temperature within the bellows enclosure to optimize lettuce germination. In addition, the lower temperature within the bellows would reduce the vapor pressure deficit (VPD) and thus evapotranspiration rate during early plant establishment.

No accumulation of salt on either the Rockwool cubes or Oasis plugs were noticed at 7 DAP and germination and seedling establishment was $>90 \%$ for all cultivars. Although the plants looked healthy, the growth rate was 3-4 days behind the same cultivars grown in pots under VEGGIE light caps that did not utilize the bellows. This could be a combination of temperature and nutrient effects, since the bellows results in a higher temperature at the plant zone, especially when the lights are on (Table 1).

Table 1: Effect of bellows enclosure on VEGGIE air temperature $\left({ }^{\circ} \mathrm{C}\right)$ with and without LED lights on.

\begin{tabular}{|l|l|l|l|}
\hline VEGGIE & Bellows & Lights Off & Lights ON \\
\hline$\# 1$ & Yes & 25.1 & 30.5 \\
\hline$\# 2$ & Yes & 25.4 & 31.0 \\
\hline$\# 3$ & No & 24.1 & 26.0 \\
\hline
\end{tabular}

CEC 3 ambient temperature $=24.1^{\circ} \mathrm{C}$.

At 11 DAP, the experiment was terminated due to severe stunting and wilting of the plants. The growth of all three cultivars on the Rockwool cubes were showing signs of severe stress, characterized by stunting, wilting, and root browning (Fig 10). Large salt crystals were forming on the surface of the root plug and roots that had developed were exhibiting tip-burn and necrosis (Fig 10). 


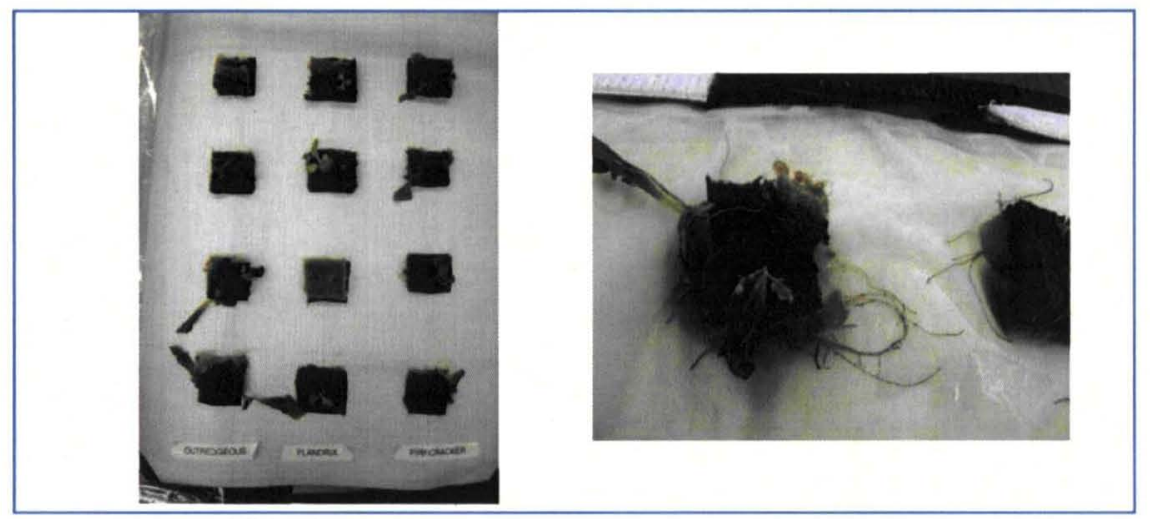

Figure 10: Lettuce plants exhibited symptoms of severe stress at 11 DAP (Left). The Rockwool plugs had significant algae growth and accumulation of salt crystal on the surface. Outredgeous leaves exhibited wilting, and roots that emerged and grew along the Nitex surface had tip burn and necrosis (Right).

There was a cultivar effect with plants started on the Oasis foam, with all the Flandria plants being necrotic at 11 DAP. Outredgeous and Firecracker had only 50\% survival at 11 DAP after planting, but they exhibited symptoms of salinity stress characterized by stunting, necrotic leaf spots, brittleness, and chlorosis (Fig 11, Fig 12). As with the Rockwool cubes, there was significant accumulation of salt crystals on the surface of the Oasis plugs.

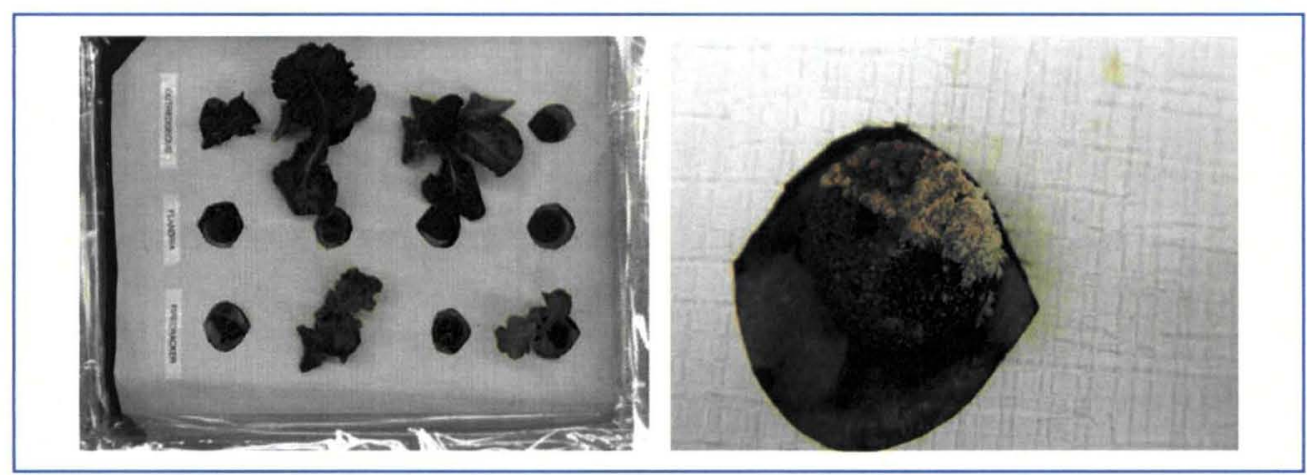

Figure 11: Red leaf cultivars, Outredgeous and Firecracker, established better than the green bibb cultivar Flandria on the Oasis plugs. However, they exhibited signs of severe stress (Left). There was significant accumulation of salt on the surface of the Oasis plugs (Right).

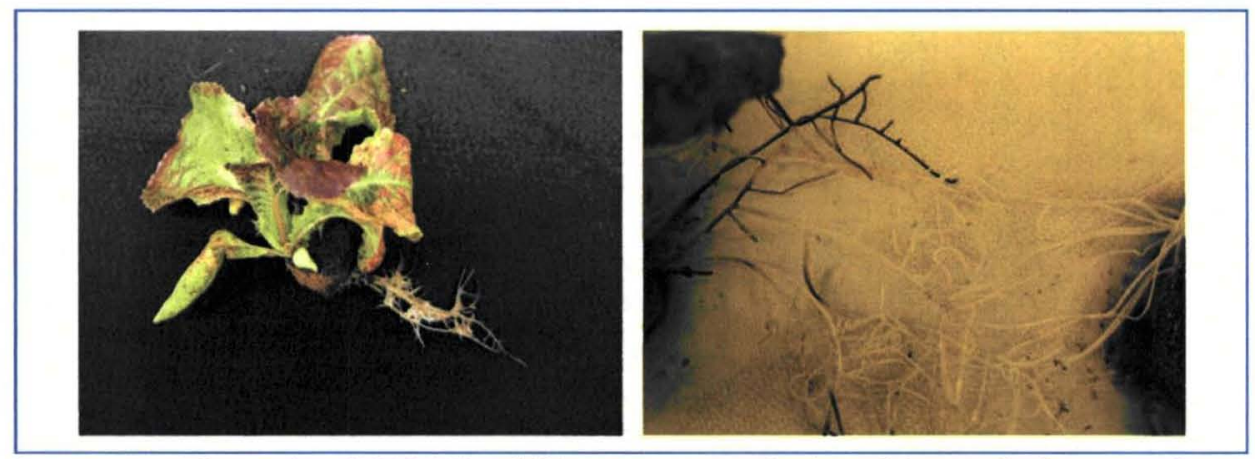

Figure 12: Lettuce cv. Firecracker (11 DAP) exhibits symptoms of salt toxicity on the leaves and roots. Note that the roots developed out from the Oasis plug and along the surface of the Nitex (Left). Roots that emerged from the Oasis plug exhibited several symptoms of distress, including tip browning and necrosis (Right). 
In order to determine whether the decline was associated with salt build up, nutrient solution was expressed from the 12 Rockwool cubes and combined for analysis. It was not possible to express a sufficient amount of solution from the Oasis blocks for nutrient analysis. Samples of nutrient solution from the VEGGIE nutrient reservoir were also collected for baseline analysis. The $\mathrm{pH}$ and EC were measured, and then the elemental composition determined using inductively coupled plasma (ICP) spectrometry or ion chromatograph (IC). The $\mathrm{pH}, \mathrm{EC}$ and elemental composition of nutrient solution in the Rockwool (RW), 1/2 strength Hoagland's solution (S), and the ratio of RW/S were determined.

The $\mathrm{pH}$ of the RW was slightly higher than the $\mathrm{S}$, but not in the phytotoxic range. This result is expected given the lack of $\mathrm{pH}$ control of the nutrient solution. However, the EC was $10 \mathrm{X}$ higher in the RW than the $\mathrm{S}$ and was in the phytotoxic range. The high $\mathrm{EC}$ within the root zone is consistent with the very high concentrations of individual ions determined from using ICP and IC analysis. These results strongly suggest that the poor growth response was due to the phytotoxic accumulation of inorganic nutrients (i.e., salts) in the lettuce root zone.

This was an unexpected result, since both Rockwool and Oasis foam have been successfully used to support plant growth in ground and flight experiments in the PI's lab for many years. In fact, Rockwool is the de facto standard rooting matrix in commercial hydroponic production of many vegetable crops.

It was hypothesized that the high water vapor pressure deficit, coupled with a high surface to volume ratio of the Rockwool, resulted in the higher rate of salt deposition observed in previous and ongoing experiments using the same media.

To examine this hypothesis, the surface/volume rations of the media were determined for the VEGGIE root plugs and compared to rooting media used for surface system tests. A comparison of the media used in the two systems, and the corresponding environmental conditions were obtained from chamber environmental monitoring (3/29/10) data and summarized in Table 2.

Table 2. Comparison of dimensions of Rockwool cubes used in surface system configurations and flight configuration, and the effects the VEGGIE bellows enclosure on temperature, $\mathrm{RH}$, and water vapor pressure deficit (VPD).

\begin{tabular}{|l|l|l|l|l|l|l|l|}
\hline System & $\begin{array}{l}\text { Rockwool } \\
\text { Dimensions } \\
(\mathrm{cm})\end{array}$ & $\begin{array}{l}\text { Total } \\
\text { Volume } \\
\left(\mathrm{cm}^{3}\right)\end{array}$ & $\begin{array}{l}\text { Exposed } \\
\text { Surface } \\
\text { Area }\left(\mathrm{cm}^{2}\right)\end{array}$ & $\begin{array}{l}\text { Surface/Vol } \\
\left(\mathrm{cm}^{2} / \mathrm{cm}^{3}\right)\end{array}$ & $\begin{array}{l}\text { Temp } \\
\left({ }^{\circ} \mathrm{C}\right)\end{array}$ & $\begin{array}{l}\text { RH } \\
(\%)\end{array}$ & VPD \\
\hline $\begin{array}{l}\text { VEGGIE- } \\
\text { flight } \\
\text { configuration }\end{array}$ & $2 \times 2 \times 2$ & 8 & 20 & 2.5 & 31 & 45 & 2.47 \\
\hline $\begin{array}{l}\text { BPSe-surface } \\
\text { configuration }\end{array}$ & $5 \times 5 \times 8$ & 200 & 25 & 0.125 & 24 & 54 & 1.37 \\
\hline
\end{tabular}

BPSe = Biomass Production System Education units, which are similar to the VEGGIE with a conventional watering system and compact fluorescent lamps instead of LEDs.

It was striking that while the volume of the Rockwool blocks tested with the VEGGIE are 25X smaller than those used in the "magenta" containers in the BPSe chambers (small chambers similar to the VEGGIE but with fluorescent lighting), the evaporative surface was $80 \%$ of the evapotranspirative surface of the larger block. As a result, the ratio of evaporative surface area to buffer volume of the Rockwool of the VEGGIE system tested was 20X higher than the BPSe surface configuration. Looking at the inverse, it means that there is $1 \mathrm{~cm}^{2}$ of surface area for every $0.4 \mathrm{~cm}^{3}$ of volume in the Rockwool, compared to $1 \mathrm{~cm}^{2}$ of surface are for every $8 \mathrm{~cm}^{3}$ in the larger blocks used in the BPSe's. That coupled with an evaporative demand from a VPD up to $2 \mathrm{X}$ as high in the bellows, there was an accumulation of nutrient salts within the media to levels that were toxic.

It was concluded that the use of starter media was not a viable approach for implementation on ISS since the environmental constraints lead to the accumulation of toxic ion concentrations in the root zone, which lead to stunting, and ultimate collapse of the crop. 


\section{Development of "Rooting Pillows" for crop production.}

The objective of these tests was to examine an entirely different approach and see if the VEGGIE rooting mat would be able to support lettuce growth in a pouch containing rooting media and controlled release fertilizer.

As shown in the previous three experiments, direct planting on Nitex and the use of starter materials attached to the media are not viable approaches to plant production on the VEGGIE root mats under microgravity conditions. An alternative approach was taken to determine whether a self-contained, pre-seeded, planting cartridge could be developed that would: 1) limit crew operations, 2) support plant growth, and 3) allow for sustained/repeated plantings. This would produce virtual 'pots' that provide aeration and nutrients to the roots. By filling the VEGGIE rooting reservoir with DI water only, the evapotranspiration drive deposition of salt on the wicking surface would be negligible.

Twelve "Rooting Pillows" were constructed by cutting pieces of opaque greenhouse plastic, removing a "window" from the bottom, and heat welding a Nitex window/wick to the opening (Fig 13).
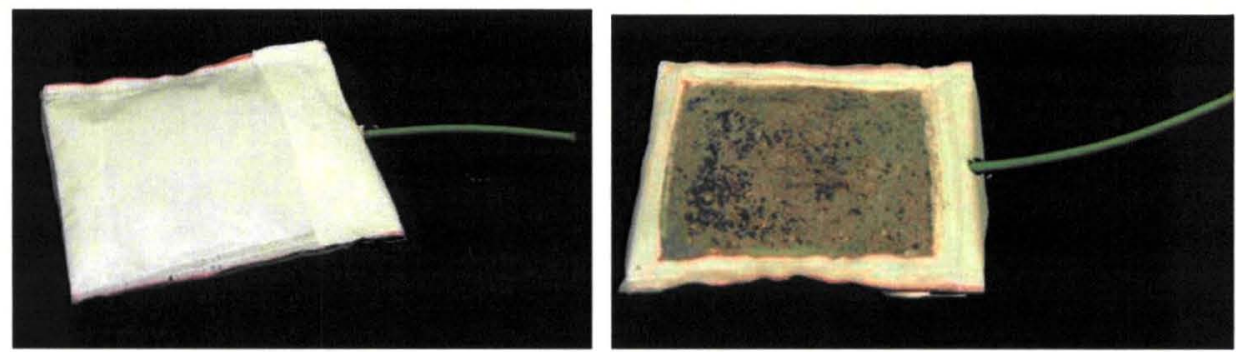

Figure 13: , Top view of rooting pillow constructed from opaque black/white greenhouse plastic (Left) Bottom view of "Rooting Pillow" showing Nitex barrier heat welded onto the pouch (Right). The rooting pillow was filled with media (arcillite) and slow release fertilizer. The water priming line is visible (green tube) in both images.

The sides of the pillow were then heat sealed, a circular watering tube inserted into the end to allow for priming, and the "rooting pillow" filled with either 1-2 mm arcillite (calcined clay chips) with $15 / \mathrm{g}$ L Osmocote time-release fertilizer added, or a peat/vermiculite mixture with $15 \mathrm{~g} / \mathrm{L}$ Osmocote added (Fig 14). The end of the packet was sealed with tape. Two holes were cut into the top surface and 2 seeds of lettuce cv. Outredgeous planted per hole.
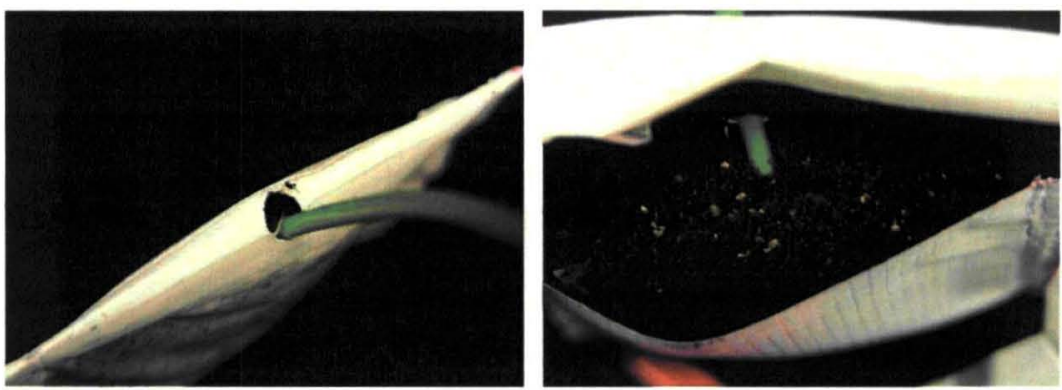

Figure 14 Access hole for water priming line (Left). Inside of rooting pillow with media (peat vermiculite) packed around the priming line prior to sealing (Right).

The VEGGIE rooting mat reservoir was filled with $\sim 1.5 \mathrm{~L}$ of DI water. The "Rooting Pillow" was primed with $100 \mathrm{ml}$ of DI water and the Nitex surface placed directly on the Nomex wick of the VEGGIE root mat. Six "rooting pillows" were placed on each of the root mats (Fig 15). 

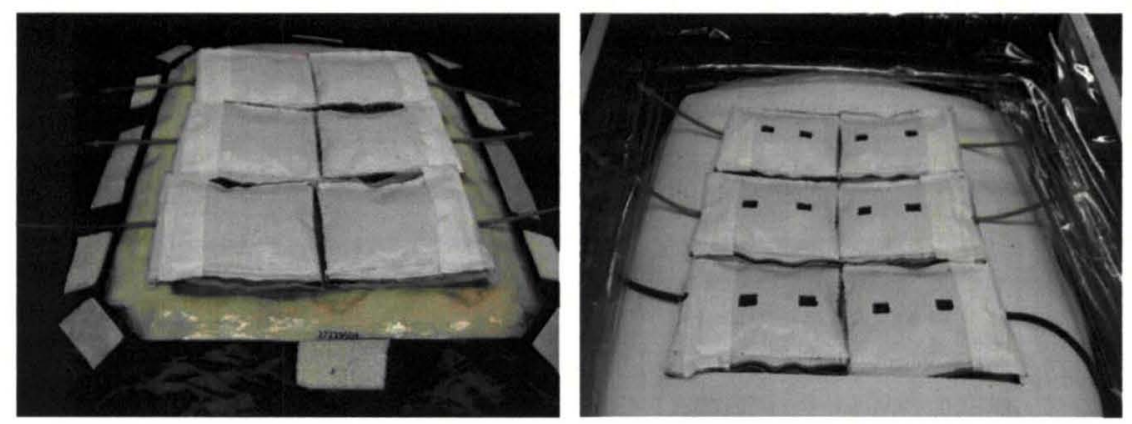

Figure 15: Placement of sealed "Rooting Pillows on the VEGGIE root mat prior to planting and covering with opaque plastic (Left). Rooting pillows planted with 2 seeds per pillow on the rooting mat (Right) Note the inclusion of an opaque cover on the VEGGIE rooting reservoir in order to minimize evaporative surface. In addition, the cover blocks light from reaching the Nomex material and minimizes the growth of algae on the mat surface.

The VEGGIE root mat was placed into the bellows enclosure and then installed under the $1^{\text {st }}$ Generation VEGGIE LED arrays as previously described (Fig 15).This configuration resulted in excellent germination in all treatments, and good vegetative and root growth at 14 DAP. AT 14 DAP, lettuce cv. Outredgeous growth looked normal and root growth was well distributed throughout both the arcillite and peat/vermiculite media (Fig. 16).

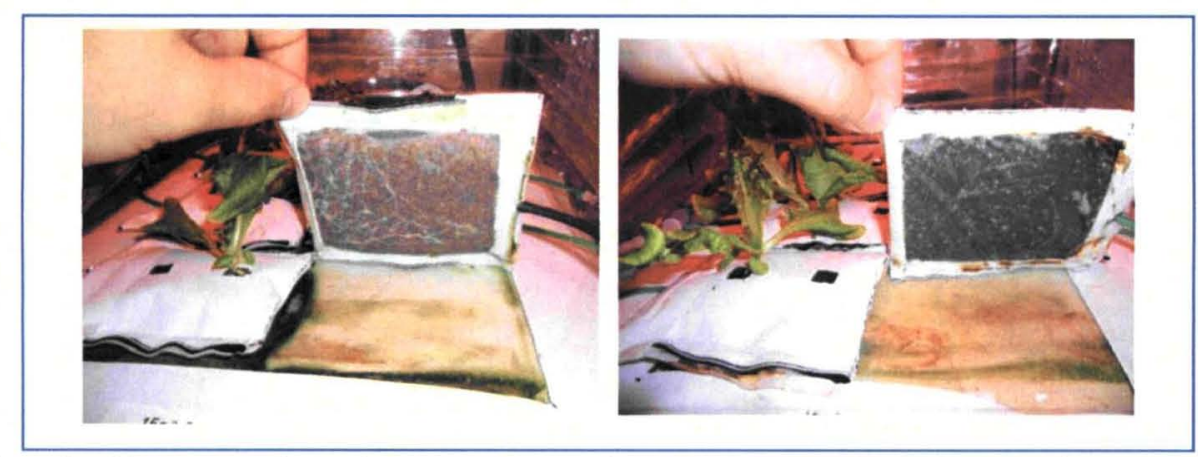

Figure 16: Growth of lettuce cv. Outredgeous at 14 DAP in prototype "Rooting Pillows" using either arcillite (Left) or commercial peat vermiculite mixture (Right) supplemented with a controlled release fertilizer as the rooting media.

This experiment was continued and the lettuce harvested at 28 DAP. Outredgeous developed good leaf color, and no symptoms of phytotoxicity observed (Figure 17).

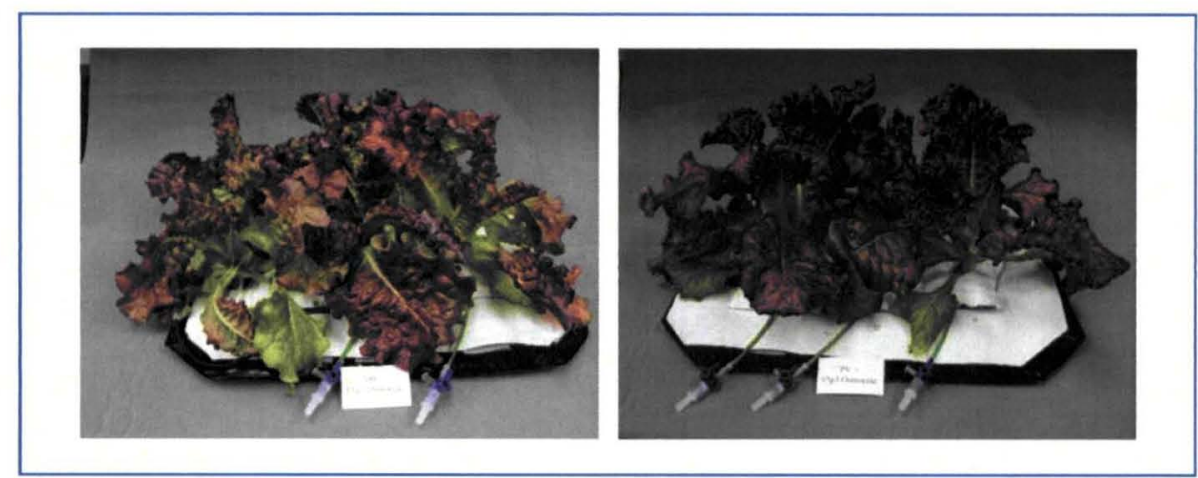

Figure 17. Lettuce cv. Outredgeous growth at 28 DAP on "Rooting Pillows" using either arcillite (Left) or commercial peat/vermiculite mixture (Right) supplemented with controlled release fertilizer as the rooting media. The plants were maintained with periodic additions of DI water to VEGGIE root mat reservoir. 
In addition to supporting excellent germination, seedling development, and color formation (Fig 17), the yield of Outredgeous lettuce grown on the "Rooting Pillows" was comparable to those obtained from Outredgeous ground in pots with bottom irrigation system (Fig 18). Yields were slightly better when plants were grown using the commercial peat / vermiculite mix than arcillite.

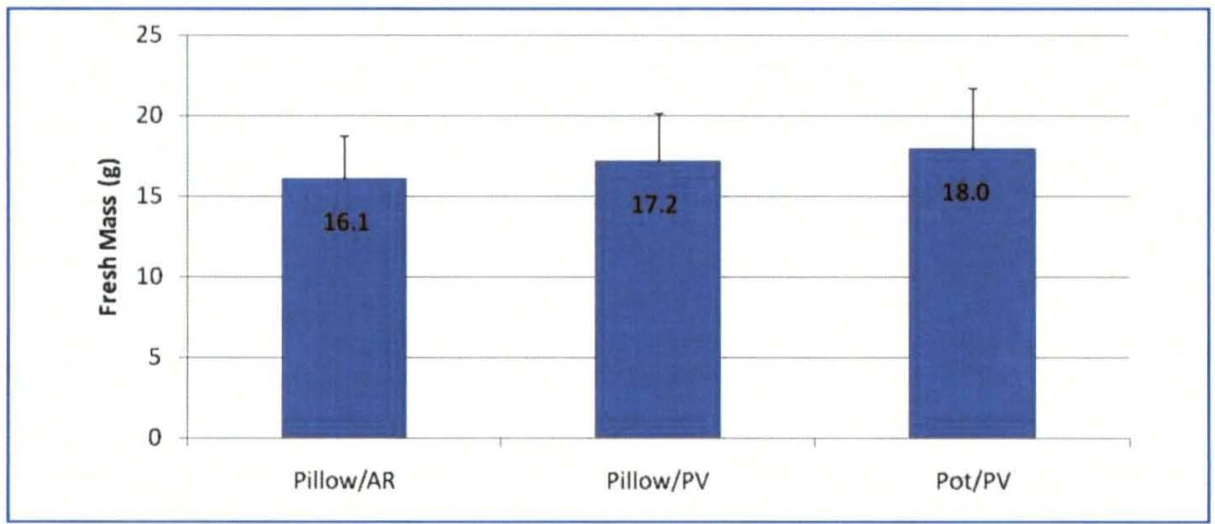

Figure 18: Fresh mass $(\mathrm{g})$ of lettuce cv. Outredgeous grown in rooting pillows using either arcillite (AR) or peat/vermiculite (PV) as the rooting media. Yields were compared to Outredgeous plants grown in pots using a peat/vermiculite mixture.

This configuration had nearly complete coverage of the VEGGIE rooting mat Nomex wicking surface, and thus minimized algae growth as well (Fig 19).

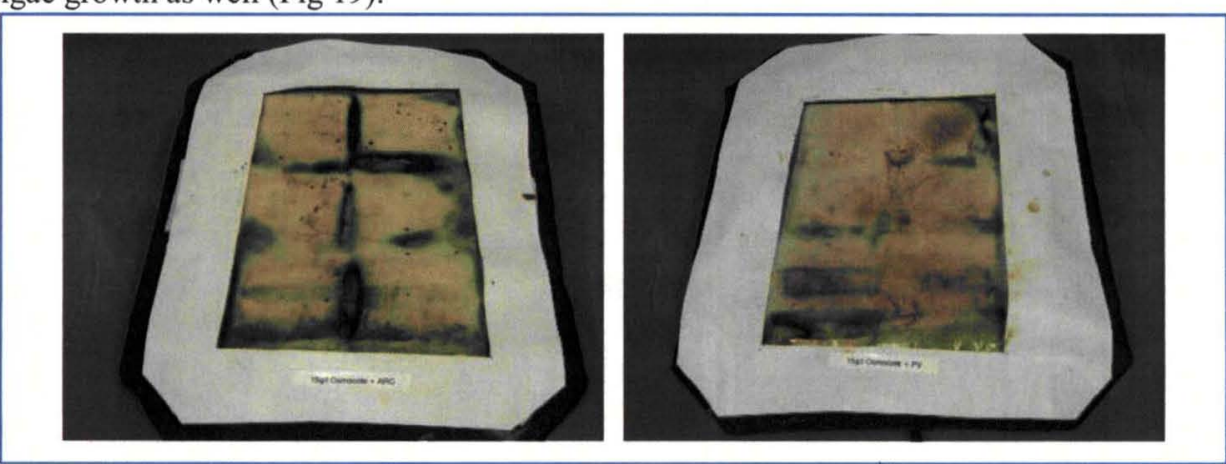

Figure 19: Algae growth on VEGGIE rooting mat surface after 28day production cycle.

Further, root growth within the "Rooting Pillows" was excellent and exhibited no characteristic signs of nutrient toxicity, such as root necrosis or tip burn. There was excellent distribution of the roots throughout the media and across the Nitex surface. The roots did not penetrate though the Nitex barrier. except where there were breaks in the Nitex / plastic heat weld (Fig 20).

Staining of the plastic pillow due to tannins leaching from the peat/vermiculate mixture was observed in the commercial potting mixture treatment, but this had no apparent impact on lettuce growth. 


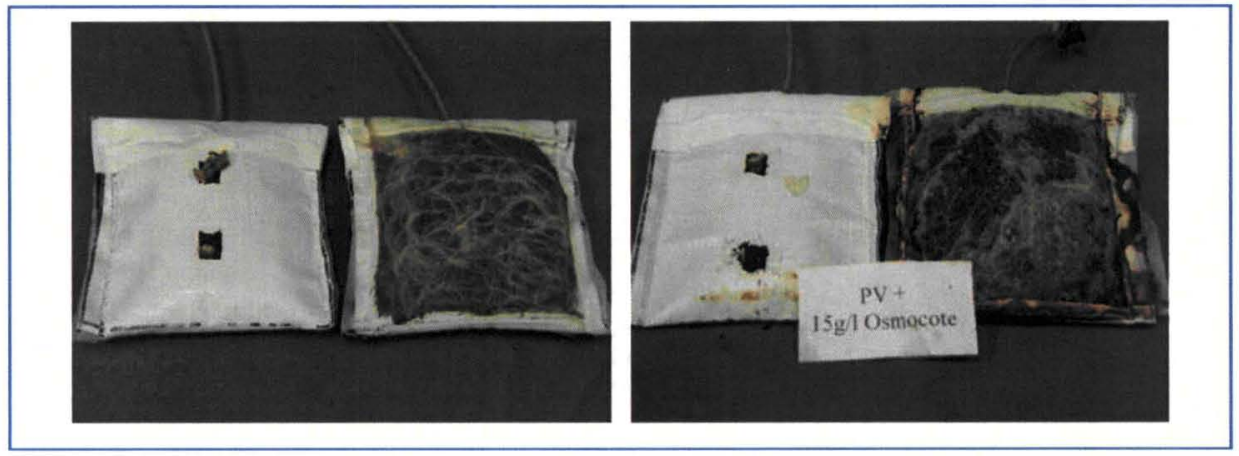

Figure 20: Root growth with the "Rooting Pillows" was evenly distributed, showed excellent branching, and no signs of nutrient toxicity or salt build-up.

Operationally, the only maintenance was periodic addition of DI water to the VEGGIE rooting mat reservoir though a quick disconnect fitting. There was no active monitoring or control of nutrient composition or water content of the media.

\section{Lettuce growth in rooting pillows under the $2^{\text {nd }}$ Generation VEGGIE LED array}

The The second generation VEGGIE LED array was delivered to Kennedy Space Center on 7 May 2010 (Fig 1). After the initial checkout of the VEGGIE LED array to confirm that the design requirements had been met, an experiment was conducted to determine whether plant growth under the new array was comparable to the $1^{\text {st }}$ generation VEGGIE prototype.

To implement this experiment, the growth of the lettuce $\mathrm{cv}$. Outredgeous using the rooting pillows, described above was compared between the $1^{\text {st }}$ and $2^{\text {nd }}$ Generation VEGGIE arrays at the same PAR $\left(\sim 250 \mu \mathrm{mol} \mathrm{m}^{-2} \mathrm{~s}^{-1}\right)$. The LOW light setting was chosen in order to compare the distribution of light, and the resulting growth responses between the $1^{\text {st }}$ and $2^{\text {nd }}$ Generation VEGGIE arrays. The comparison used a commercial peat/vermiculite mix as the rooting media and Nutricote time release fertilizer at either 7.5 or $15 \mathrm{~g} / \mathrm{L}$ as the nutrient source. Seeds were planted in the custom made "Rooting Pillows" as described above and harvested at 28 DAP.

Two plants were established for each "Rooting Pillow". Germination was $>90 \%$ in all cases, but interplant shading typically resulted in the decline of one of the plants per pillow. The total number of plants was either 7 or 8 per VEGGIE root mat.

At the LOW light level, the $2^{\text {nd }}$ generation VEGGIE array resulted in lettuce cv. Outredgeous plants that were taller, had more leaf area, and greater fresh and dry mass than the plants grown under the $1^{\text {st }}$ generation VEGGIE array (Fig 21, 22).

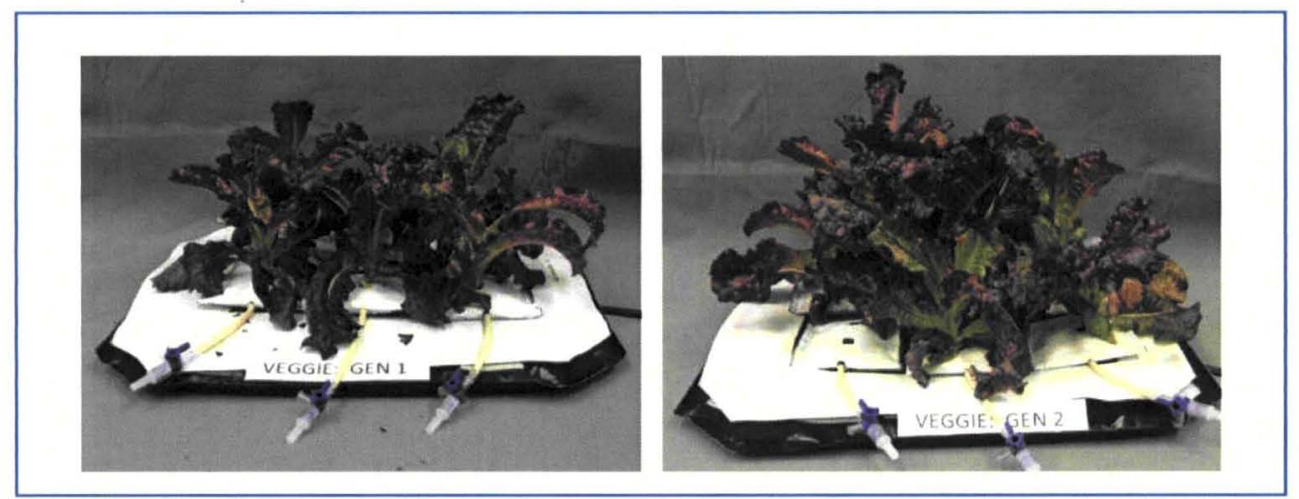

Figure 21. 28 Day old lettuce cv. Outredgeous grown in "Rooting Pillows" with $15 \mathrm{~g} / \mathrm{L}$ Nutricote fertilizer under the $1^{\text {st }}$ Generation VEGGIE LED array (Left) and $2^{\text {nd }}$ Generation VEGGIE LED array (Right). 


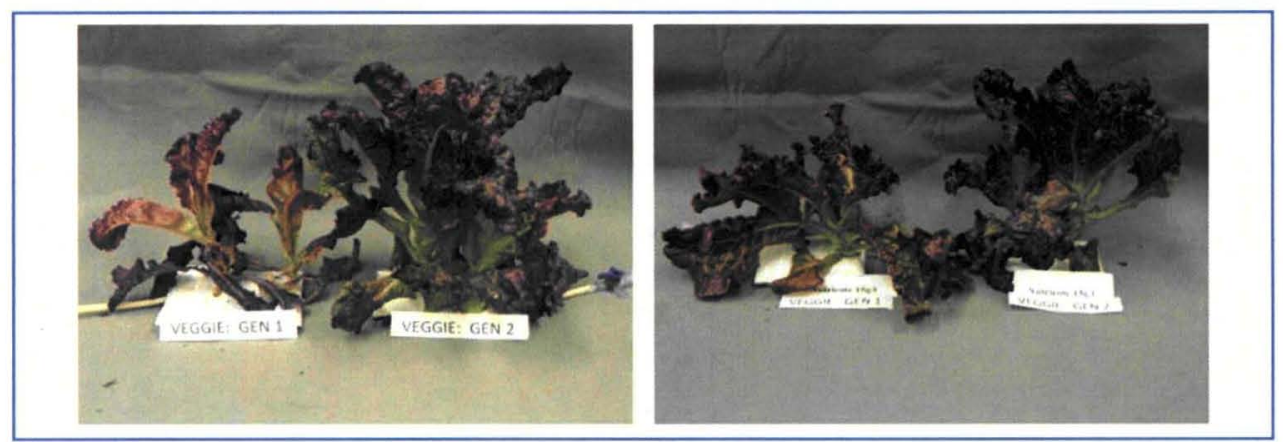

Figure 22: 28 Day old lettuce cv. Outredgeous grown in "Rooting Pillows" with $15 \mathrm{~g} / \mathrm{L}$ Nutricote fertilizer under the $1^{\text {st }}$ and $2^{\text {nd }}$ Generation VEGGIE LED arrays at either $15 \mathrm{~g} / \mathrm{L}$ (Left) or $7.5 \mathrm{~g}$ Nutricote (Right) in commercial peat/vermiculite mixture.

Outredgeous lettuce grown under the $2^{\text {nd }}$ Generation VEGGIE LED array had less leaf elongation, and greater color development than plants grown under the $1^{\text {st }}$ Generation VEGGIE LED arrays. This is likely due the greater percentage of blue light in the $2^{\text {nd }}$ Generation array.

Threre no significant differences in plant height, fresh mass or leaf area between the $1^{\text {st }}$ and $2^{\text {nd }}$ Generation VEGGIE Light arrays (Table 6) of Outredgeous grown with $7.5 \mathrm{~g} / \mathrm{L}$ Nutricote, but there was a trend to more chlorophyll and anthocyanin (red pigment) being produced with the $2^{\text {nd }}$ Generation VEGGIE LED array. In contrast, when Outredgeous was grown using $15.0 \mathrm{~g} / \mathrm{L}$ of Nutricote in the rooting pillows, the $2^{\text {nd }}$ Generation VEGGIE LED arrays resulted in plants that were significantly taller, had greater fresh mass, dry mass and leaf area (Table 6). This is consistent with observations shown in Figures 21 and 22. Anthocyanin concentration and ORAC (Oxygen Radical Absorbance Capacity) potential were lower in Outredgeous grown under the updated arrays. This was likely due to a "dilution" effect associated with the greater biomass, as well as intracanopy shading of blue light necessary to sustain anthocyanin synthesis in the leaves.

Plant growth could be sustained for up to 28 days using the "Rooting Pillow" production method with minimal plant maintenance and yield of Outredgeous lettuce produced under the $2^{\text {nd }}$ Generation VEGGIE LED array was as good or greater than that obtained with $1^{\text {st }}$ Generation VEGGIE array. Production of comparable or greater yields of lettuce under the $2^{\text {nd }}$ Generation VEGGIE LED array was achieved with $~ 50 \%$ of the power necessary to produce the same yields with the $1^{\text {st }}$ Generation arrays.

Table 6: Comparison of growth 28 day lettuce cv. Outredgeous between $1^{\text {st }}$ and $2^{\text {nd }}$ Generation VEGGIE LED arrays. Plants were grown in VEGGIE rooting "pillows" using commercial peat/vermiculite mix with either $7.5 \mathrm{~g} / \mathrm{L}$ Nutricote controlled release fertilizer prills (mean \pm standard error).

\begin{tabular}{|c|c|c|c|c|c|c|}
\hline & \multicolumn{6}{|c|}{ Biometric Data } \\
\hline VEGGIE & $\begin{array}{l}\text { Height } \\
(\mathrm{mm})\end{array}$ & FM (g) & DM (g) & $\begin{array}{l}\begin{array}{l}\text { Leaf } \\
\left(\mathrm{cm}^{2}\right)\end{array}\end{array} \quad$ Area & LAI & $\operatorname{SLM}\left(\mathrm{mg} / \mathrm{cm}^{2}\right)$ \\
\hline $1^{\text {st }}$ Gen & $73 \pm 6.5$ & $2.14 \pm 0.37$ & $0.27 \pm 0.08$ & $71 \pm 12.6$ & $0.57 \pm 0.10$ & $3.82 \pm 1.09$ \\
\hline \multirow[t]{3}{*}{$2^{\text {nd }} \mathrm{Gen}$} & $67 \pm 7.8$ & $2.00 \pm 0.47$ & $0.25 \pm 0.06$ & $71 \pm 15.9$ & $0.57 \pm 0.13$ & $4.71 \pm 2.34$ \\
\hline & \multicolumn{6}{|c|}{ Quality data } \\
\hline & \multicolumn{3}{|l|}{ Color } & \multirow{2}{*}{$\begin{array}{l}\text { Chloro } \\
\text { (SPAD) }\end{array}$} & \multirow{2}{*}{$\begin{array}{l}\text { Antho } \\
\text { (ug/g FM) }\end{array}$} & \multirow{2}{*}{$\begin{array}{l}\text { ORAC } \\
\text { (TE/g FM) }\end{array}$} \\
\hline VEGGIE & $\mathrm{L}$ & $\mathrm{a}$ & $\mathrm{b}$ & & & \\
\hline 1st Gen & $31.1 \pm 0.92$ & \begin{tabular}{|l|l|}
$7.7 \pm 0.89$ \\
\end{tabular} & $4.9 \pm 0.65$ & $18.7 \pm 1.33$ & $1288 \pm 165$ & $36.0 \pm 4.2$ \\
\hline 1st Gen & $26.4 \pm 0.54$ & $8.4 \pm 0.93$ & $1.1 \pm 0.42$ & $22.7 \pm 2.31$ & $1777 \pm 342$ & $26.7 \pm 6.0$ \\
\hline
\end{tabular}

FM and DM $=$ Fresh mass and dry mass, respectively.

$\mathrm{LAI}=$ Leaf area index in $\mathrm{m}^{2}$ of leaves above $\mathrm{a} \mathrm{m}^{2}$ of ground area.

SLM $=$ Specific leaf mass, which measures the density of leaf tissue.

$\mathrm{SPAD}$ values refer to readings taken with a commercial chlorophyll detection meter.

ORAC $=$ Oxygen Radical Absorbance Capacity and is a measure of antioxidant capacity.

Antho $=$ Anthocyanin, or the reddish / purple pigment in plants which is an antioxidant. 
Table 7: Comparison of growth 28 day lettuce $\mathrm{cv}$. Outredgeous between $1^{\text {st }}$ and $2^{\text {nd }}$ Generation VEGGIE LED arrays. Plants were grown in VEGGIE pillows using commercial peat/vermiculite mix with either $15 \mathrm{~g} / \mathrm{L}$ Nutricote controlled release fertilizer prills (mean \pm standard error).

\begin{tabular}{|c|c|c|c|c|c|c|}
\hline & \multicolumn{6}{|c|}{ Biometric Data } \\
\hline VEGGIE & $\begin{array}{l}\text { Height } \\
(\mathrm{mm})\end{array}$ & FM (g) & $\mathrm{DM}(\mathrm{g})$ & $\begin{array}{l}\text { Leaf } \\
\left(\mathrm{cm}^{2}\right)\end{array} \quad$ Area & LAI & $\mathrm{SLM}\left(\mathrm{mg} / \mathrm{cm}^{2}\right)$ \\
\hline $1^{\text {st }}$ Gen & $119 \pm 10.2$ & $4.9 \pm 0.85$ & $0.68 \pm 0.26$ & $141 \pm 27.9$ & $1.13 \pm 0.22$ & $4.76 \pm 1.04$ \\
\hline \multirow[t]{3}{*}{$2^{\text {nd }}$ Gen } & $148 \pm 14.4$ & $8.8 \pm 1.61$ & $0.92 \pm 0.18$ & $256 \pm 44.9$ & $2.05 \pm 0 . .36$ & $3.53 \pm 0.18$ \\
\hline & \multicolumn{6}{|l|}{ Quality data } \\
\hline & \multicolumn{3}{|l|}{ Color } & \multirow{2}{*}{$\begin{array}{l}\text { Chloro } \\
\text { (SPAD) }\end{array}$} & \multirow{2}{*}{$\begin{array}{l}\text { Antho } \\
\text { (ug/g FM) }\end{array}$} & \multirow{2}{*}{$\begin{array}{l}\text { ORAC } \\
\text { (TE/g FM) }\end{array}$} \\
\hline VEGGIE & $\mathrm{L}$ & $\mathrm{a}$ & $\mathrm{b}$ & & & \\
\hline $1^{\text {st }}$ Gen & $38.1 \pm 0.89$ & $4.2 \pm 1.21$ & $10.4 \pm 0.94$ & $15.1 \pm 2.5$ & $841 \pm 69$ & $83.8 \pm 0.6$ \\
\hline $1^{\text {st }}$ Gen & $36.7 \pm 1.87$ & $2.6 \pm 1.64$ & $10.3 \pm 0.75$ & $20.2 \pm 2.2$ & $662 \pm 83$ & $64.6 \pm 0.3$ \\
\hline
\end{tabular}

FM and DM $=$ Fresh mass and dry mass, respectively.

$\mathrm{LAI}=$ Leaf area index in $\mathrm{m}^{2}$ of leaves above $\mathrm{a}^{2}$ of ground area.

$\mathrm{SLM}=$ Specific leaf mass, which measures the density of leaf tissue.

SPAD values refer to readings taken with a commercial chlorophyll detection meter.

ORAC = Oxygen Radical Absorbance Capacity and is a measure of antioxidant capacity.

Antho = Anthocyanin, or the reddish / purple pigment in plants which is an antioxidant.

\section{Refinement of "pillows" as a VEGGIE nutrient delivery system}

The initial tests using Rooting Pillows made from black/white greenhouse plastic demonstrated the feasibility of using this approach to grow salad crops on the VEGGIE root mat (Fig 23). However, a number of issues were identified that will have to be resolved prior to usage on the space station. One of the first issues identified was the difficulty in achieving a strong and stable heat weld between the sheets of greenhouse plastic. Conversely, it was difficult to achieve a strong weld of the Nitex to the greenhouse plastic without excess heating of the Nitex, which resulted in melting and the development of holes in the weld which allowed roots and media to escape. A second issue was obtaining a tight seal around the end of the pillow after the rooting media/fertilizer prills and priming line were inserted. A third issue was leakage of media though the planting holes in the top of the pillows.

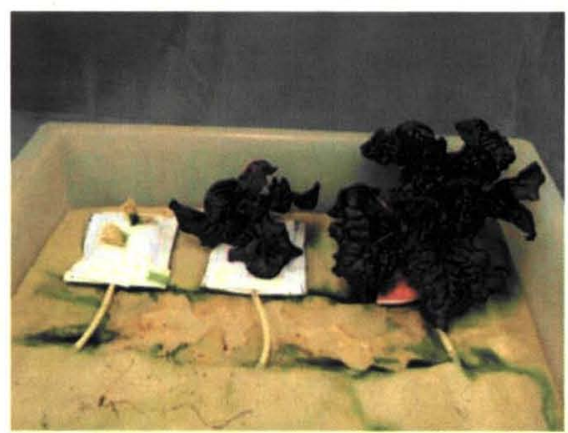

Figure 23. Sustained growth of Outredgeous lettuce in prototype "Rooting Pillows" using Nomex as seed wicking material. Lettuce cv. Outredgeous at 3,14 and 28 DAP were grown on prototype rooting pillows using an analog root mat using Nomex covered foam was used to perform initial trials.

A review of existing materials and premade bags was made in order to identify materials that that would facilitate the design and development "Rooting Pillows". Ultimately, 3 inch x 5 inch $(7.6 \mathrm{~cm} \mathrm{X} 12.7 \mathrm{~cm})$ metallic static free zip lock bags (Polybag Suppliers, Charlotte, NC) were chosen to determine feasibility of using existing bags as the basis for "Rooting Pillow" construction. The metallic bags are constructed of $2 \mathrm{~mm}$ metallic material that can be heat welded with a standard laboratory heat sealer. It was also established empirically that Nitex welded easily to the metallic bag without excessive heat being applied. A 2.5 inch x 4 inch $(6.3 \mathrm{~cm} \mathrm{X} 10.2 \mathrm{~cm})$ square was cut out of

15

American Institute of Aeronautics and Astronautics 
the bottom of the metallic bags and a rectangle of Nitex heat welded into the opening to create the water-permeable barrier to contain the rooting media and plant material (Fig 24).

A media priming line, consisting of $1 / 8$ inch circular tubing punctured with holes at $\sim 0.5 \mathrm{~cm}$ intervals, was placed into the bag. This priming line was connected with a "T" to a single line that extended external to the bag. The bag was filled with approximately $100 \mathrm{ml}$ volume $(\sim 50 \mathrm{~g}$ dry $)$ of commercial peat/vermiculite potting mix that had been enriched with $15 \mathrm{~g} / \mathrm{L}$ Nutricote. The ziplock seal was then closed, forming a relatively tight seal around the external priming line.
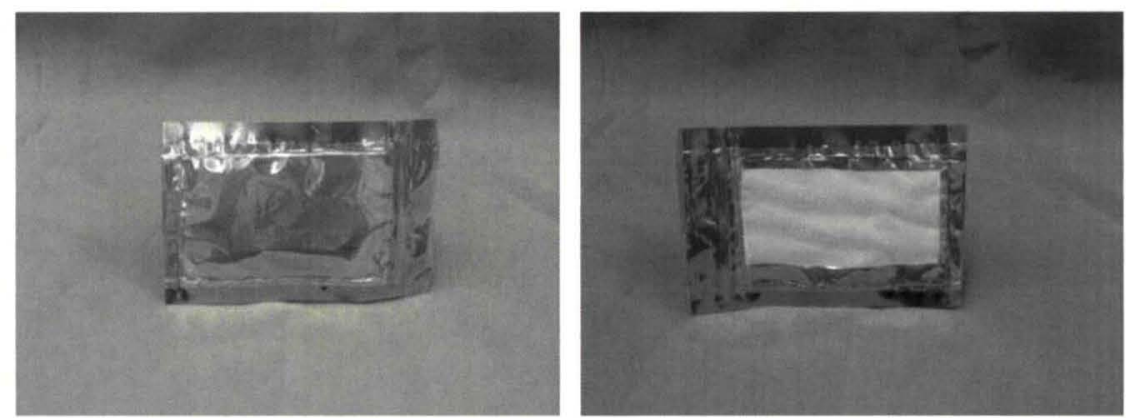

Figure 24: Top view of $2^{\text {nd }}$ generation prototype metallic rooting pillow bags Left, Bottom view of same bag showing heat welded Nitex barrier Right.

Two slits, $\sim 1 \mathrm{~cm}$ in length, were cut in the top of the rooting pillow, and two wicks made of either Nitex or Nomex were inserted into each hole. This created a crease into which a seed could be placed and be able to develop roots into the media, but not have media fall out of the pillow (Fig. 25).
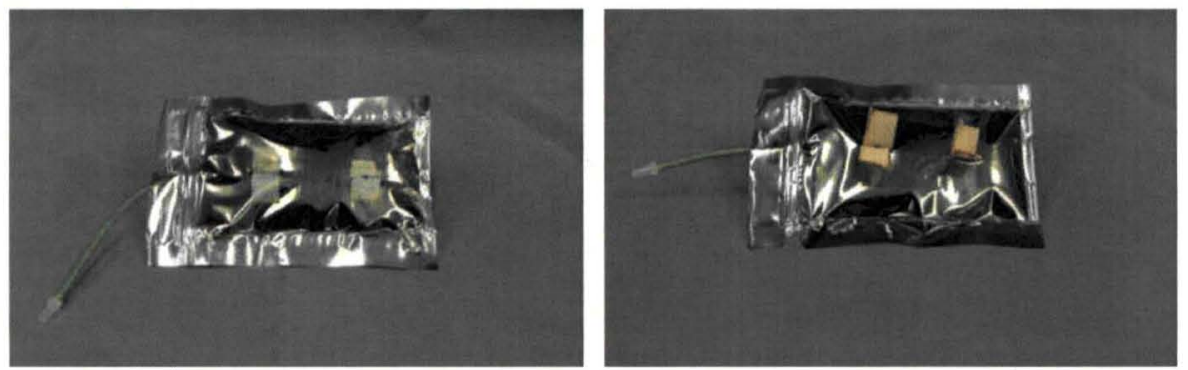

Figure 25: Top view of $2^{\text {nd }}$ generation rooting pillows with Nitex (Left) or Nomex (Right) seed wicks inserted into the top. The media priming tube is visible in both images.

To initiate planting, $\sim 100 \mathrm{ml}$ of DI water was injected into the packet in order to wet the media thought the priming tube (Fig 25). This was necessary to overcome the hysteresis associated with initial wetting of the media, and allowed equilibration with the water content of the Nomex surface of the VEGGIE rooting reservoir. A few $\mathrm{ml}$ of water were placed on each seed, and the pillow was then placed under the VEGGIE LED array, insuring good contact between the Nitex bottom of the rooting pillow and the Nomex top of the water reservoir. Water was added to the VEGGIE water reservoir on an "as needed" basis.

Germination was excellent in the $2^{\text {nd }}$ generation root mats, and initial evaluations indicated that the materials were biocompatible and leakage of water, media or roots from the rooting pillows was negligible (Fig. 26). However, a test of plant growth using $1^{\text {st }}$ and $2^{\text {nd }}$ generation VEGGE LED arrays with different wicking configurations is ongoing, and no biocompatibility issues have emerged. 


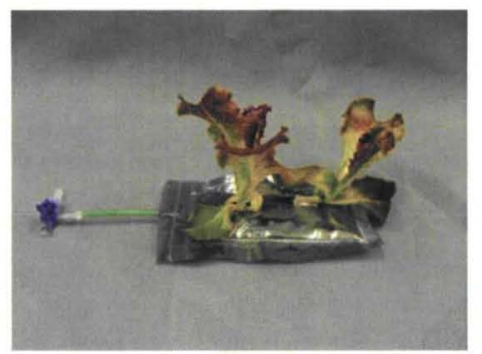

Figure 26: Growth of Outredgeous lettuce in $2^{\text {nd }}$ generation metallic rooting pillows after 14 days using a commercial peat/vermiculite mix with $7.5 \mathrm{~g}$ Nutricote. Plants were grown using $2^{\text {nd }}$ Generation VEGGIE LED arrays as the light source.

\section{Conclusions}

In order to be a viable microgravity-based salad production system, the nutrient delivery system will have to: 1) support plant growth from seed to harvest while 2) retaining water, media and plant material. These objectives must be achieved within the safety, contamination, and operational constraints of the spacecraft and the crew.

The VEGGIE LED array is designed to meet the power, space, volume, and safety constraints of the International Space Station. The rooting mat reservoir has a volume of $\sim 1.5 \mathrm{~L}$, which is within the ISS constraints of $2 \mathrm{~L}$ of water that could be added to the atmosphere without impacting ECLSS performance. The use of Nomex material for wicking, and the use of Teflon bellows provide containment of water that would be released into the cabin through evapotranspiration.

These initial designs of the "Rooting Pillows" have demonstrated the feasibility of using Nitex as a water permeable barrier to contain media, nutrient solution, and plant roots while supporting plant growth from seed to harvest. However, a number of issues were identified in the initial tests that require additional development prior to manifesting and testing on ISS.

\section{Acknowledgments}

This research was supported by NASA Innovate Partnership Program (IPP) grant.

\section{References}

Kliss, M. and R.D. MacElroy. 1990. Salad machine: A vegetable production unit for long duration space missions. SAE Tech. Paper 901280. Williamsburg, VA, USA. July 1990.

Kliss, M., A.G. Heyenga, A. Hoehn and L.S. Stodieck. 2000. Recent advances in technologies required for a "Salad Machine". Advances in Space Research 26(2):263-269.

Lane, H.W. and D.A. Schoeller. 2000. Nutrition in spaceflight and weightlessness models. CRC Press, Boca Raton. $301 \mathrm{pp}$.

Morrow, R.C. and R.W. Remiker. 2009. A deployable salad crop production system for Lunar habitats. SAE Tech. Paper 2009-01-2382.

Morrow, R.C., R.W. Remiker, M.J. Mischnich. L.K. Tuominen, M.C. Lee, and T.M. Crabb. 2005. A low ESM plant growth unit for space exploration. SAE Tech. Paper 2005-01-2843.

Stutte G.W., O. Monje, N.C. Yorio, S.L. Edney, G. Newsham, L. Connole, R.M. Wheeler. 2009. Sustained salad crop production requirements for lunar surface. SAE Tech Paper 2009-01-2381.

Sytchev, V.M., M.A. Levinskikh, S.A. Gostimsky, G.E. Bingham, and I.G. Podolsky. 2007. Spaceflight effects on consecutive generations of peas grown onboard the Russian segment of the International Spce Station. Acta Astronautica 60:426-432.

Wheeler, R.M., G.W. Stutte, G.V. Subbarao, and N.C. Yorio. 2001. Plant growth and human life support for space travel. In: M. Pessarakli (ed.), $2^{\text {nd }}$ Edition. Handbook of Plant and Crop Physiology. pp. 925-941. Marcel Dekker Inc., New York. 


\section{Concept for Sustained Plant Production on ISS Using VEGGIE Capillary Mat Rooting System}

Gary W. Stutte, PhD and Gerard Newsham, ESC-Team QNA, Kennedy Space Center, FL Robert M. Morrow, PhD ORBITEC, Madison, WI 53717

Raymond M. Wheeler, PhD NASA, Kennedy Space Center, FL 41st ICES, 17-21 July 2011

Portland, Oregon 


\section{Objective}

- Background Information

- Concept of Operations

- Developmental Work

- Media

- Seed starting

- Rooting Pillow Concept

- Description

- Results

- Conclusion 


\section{OAIAA}

VEGGIE: Background

- VEGGIE developed as part of NASA Phase II SBIR by ORBITEC (Madison, WI)

- VEGGIE has Red, Blue, Green LED light source

- Expandable greenhouse sides.

- Passive watering through

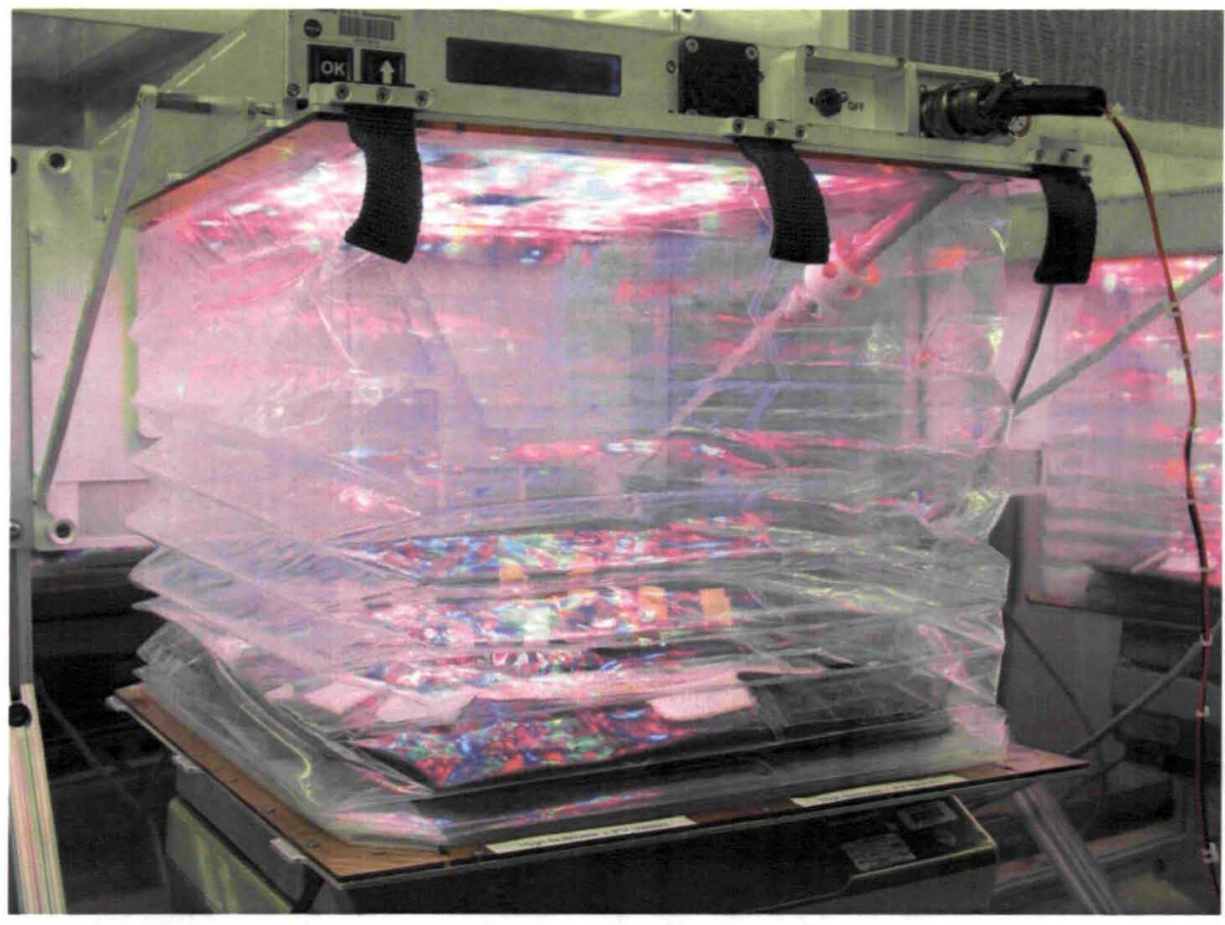
independent rooting mat. 


\section{OAIAA:}

VEGGIE Root mat: Top View

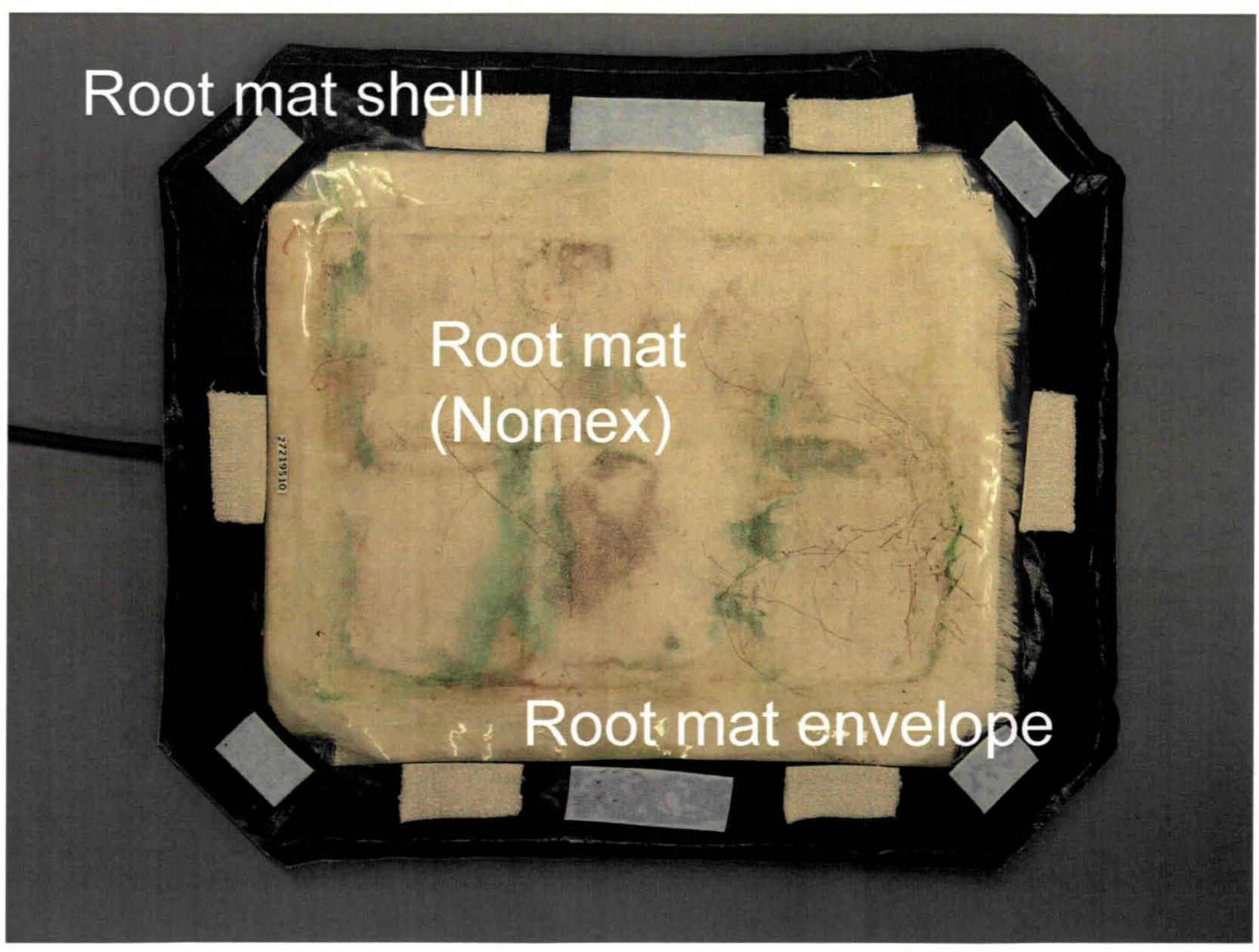




\section{OAIAA:}

\section{VEGGIE Root Mat- Component Assembly (top)}

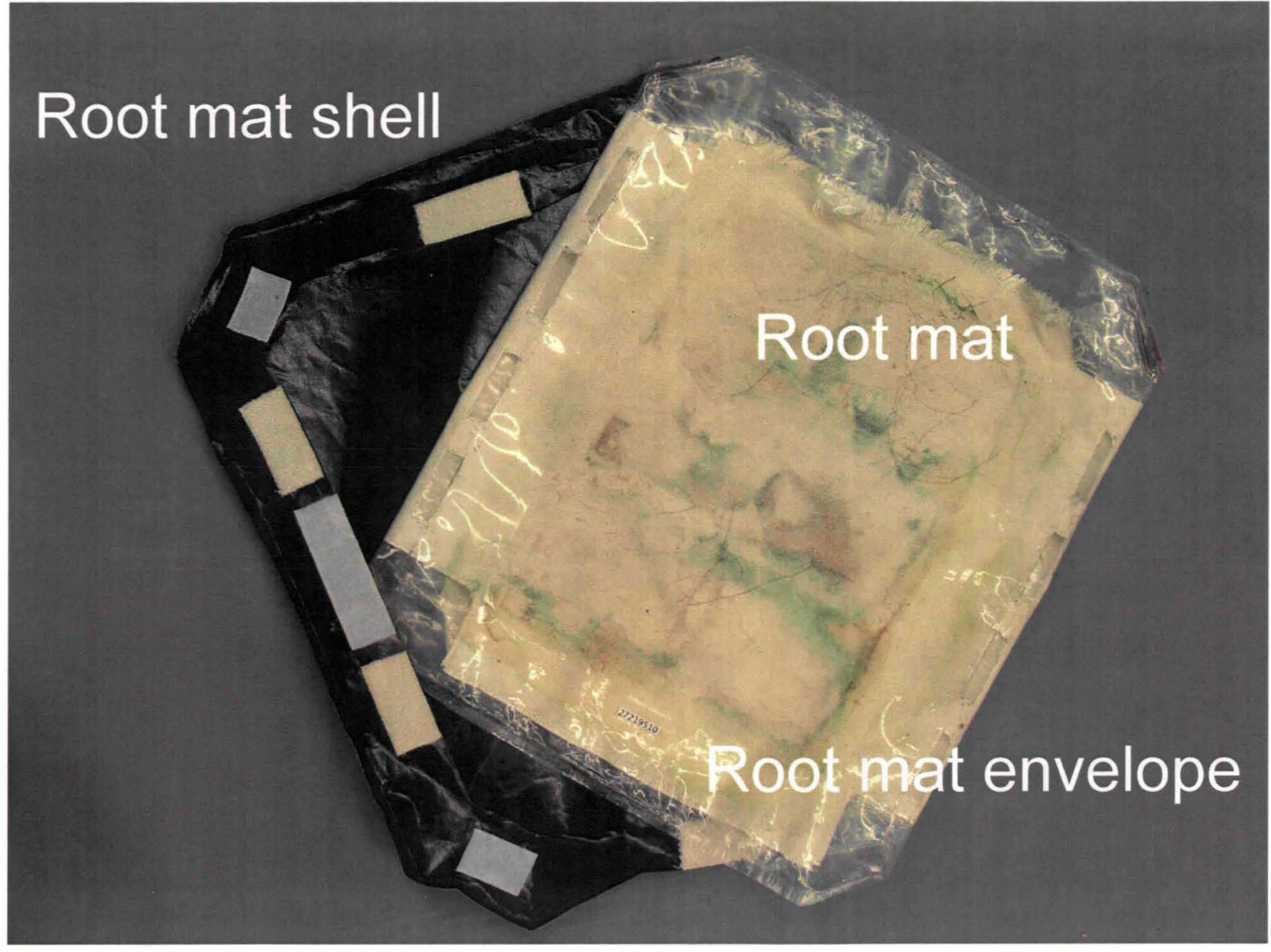




\section{OAIAA}

\section{VEGGIE Root Mat- Component Assembly (bottom)}

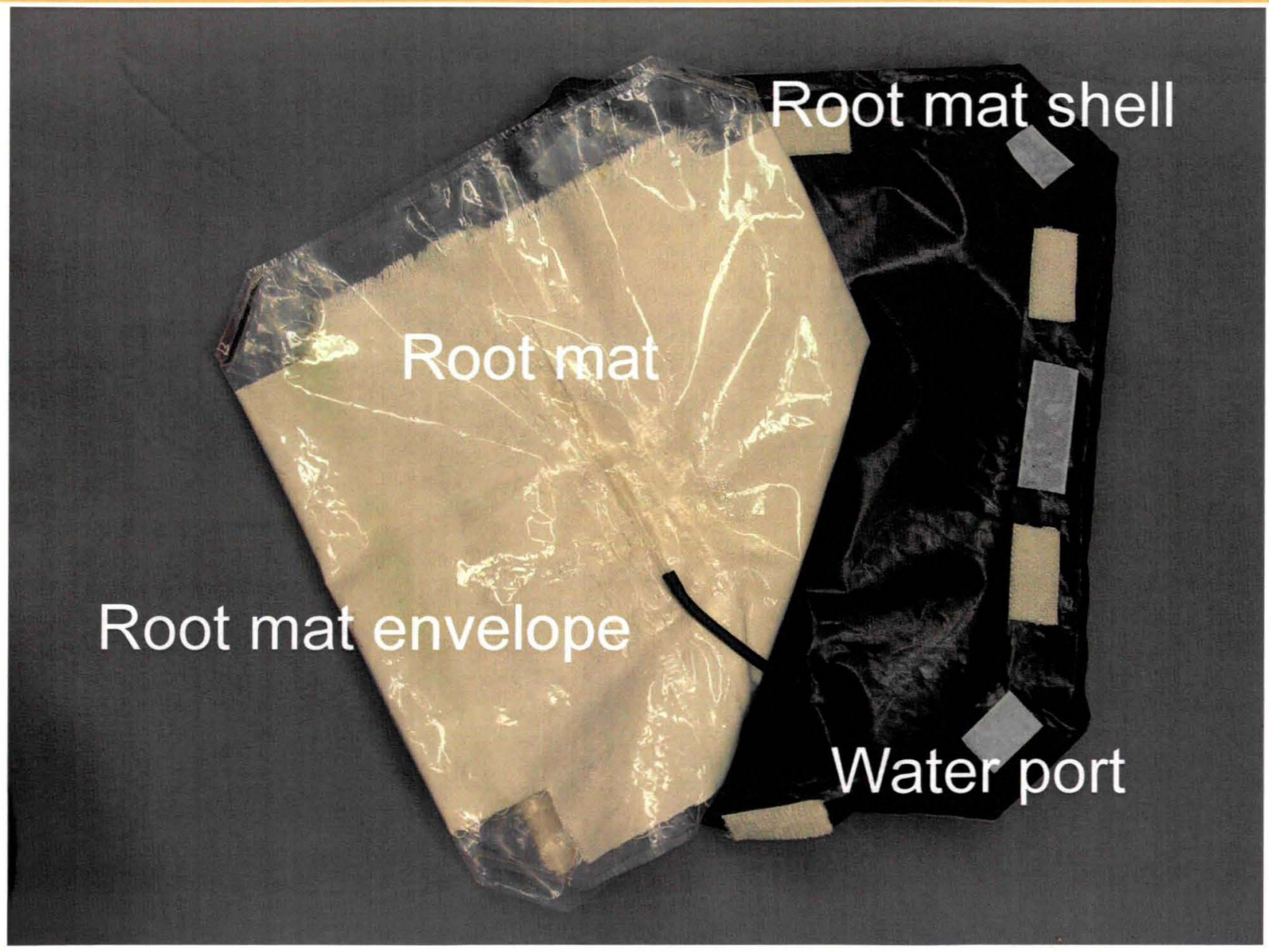




\section{Concept of Operations}

- Utilize VEGGIE root mat as primary water/nutrient delivery system.

- Planting, maintenance and harvest operations compatible with microgravity environment

- Growth system supports multiple harvest cycles.

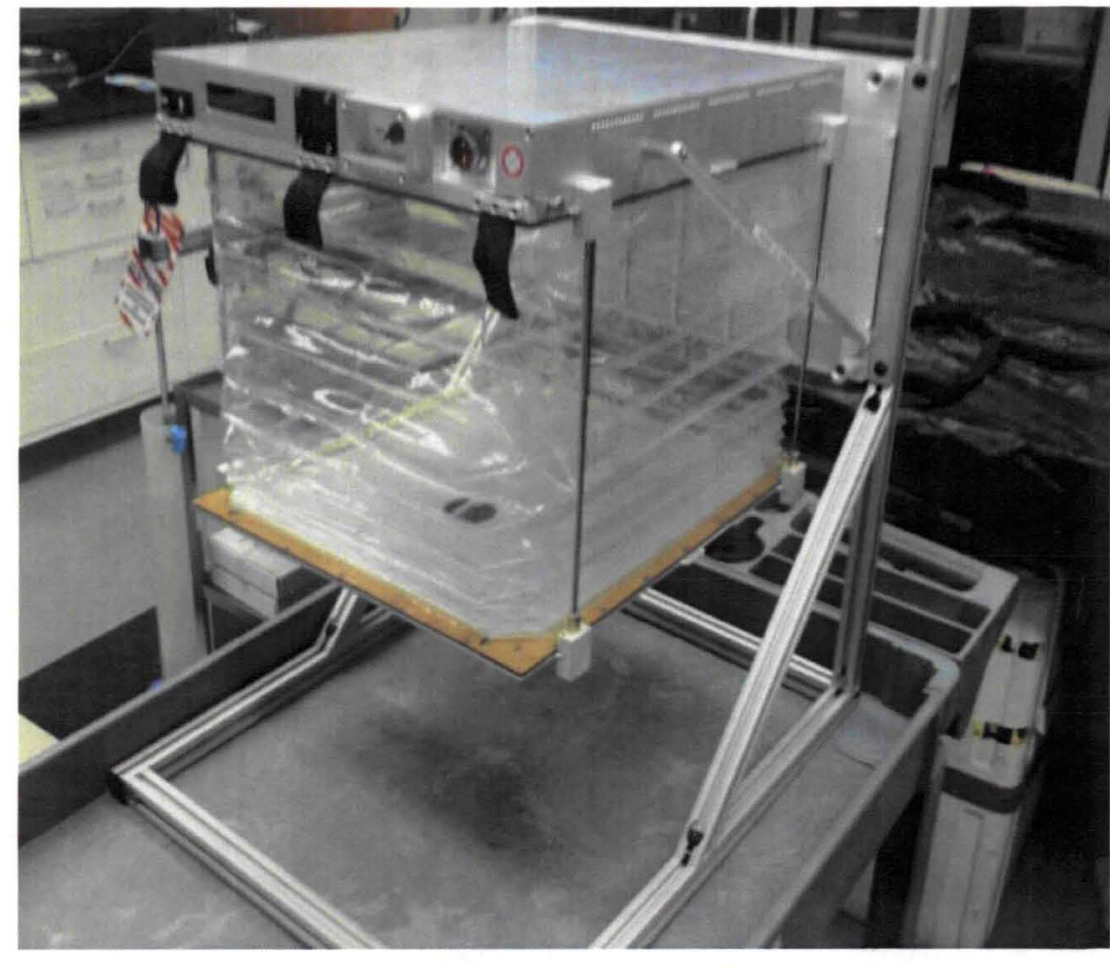

VEGGIE plant growth system with LED light cap, flexible containment, and capillary mat nutrient delivery system. 


\section{OAIAA}

Concept One: Direct seeding onto pre-planted hydrophilic material (Nitex)

- Objective-Direct seeding on rooting material without a rooting matrix

- Nitex (hydrophilic nylon) used to contain lettuce seeds.

- Nutrient solution (modified Hoagland's)

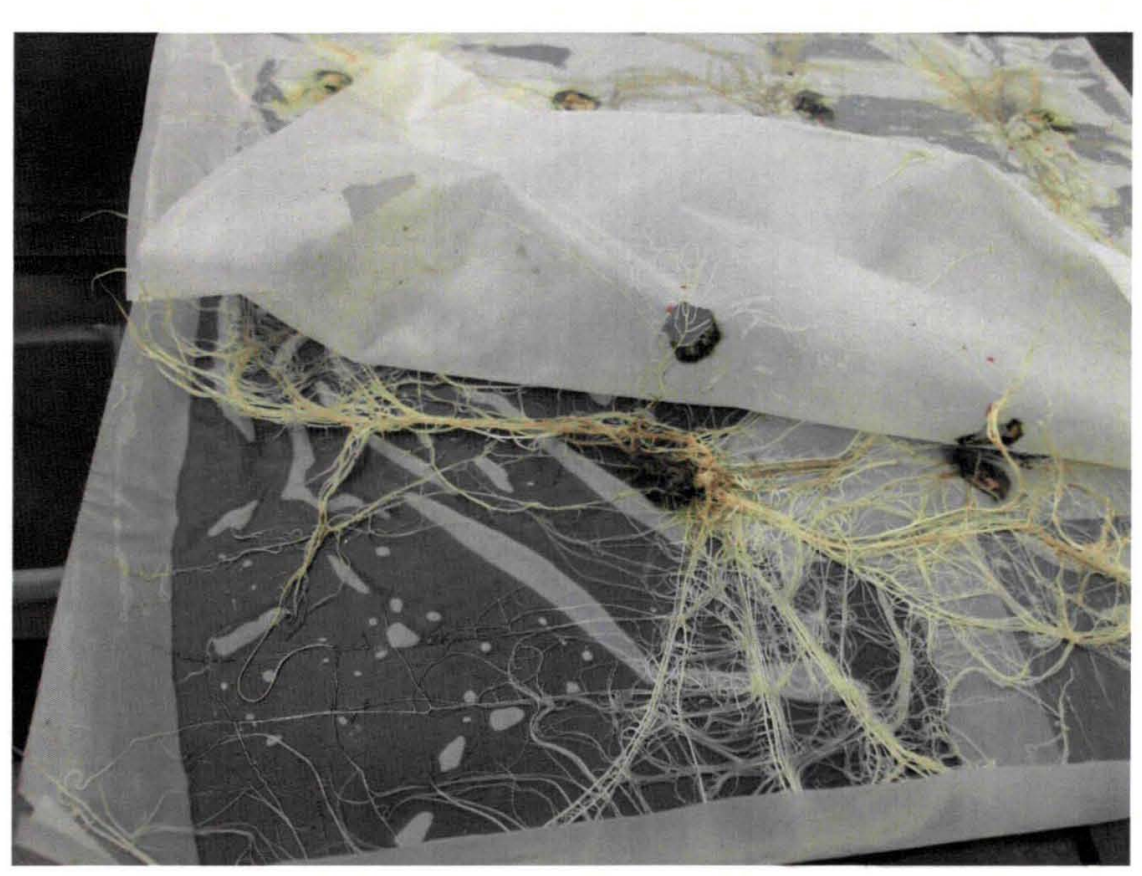
provided through Nomex wick of nutrient reservoir. 


\section{OAIAA}

Direct seeding on Nitex had good germination, but did not support full development of lettuce
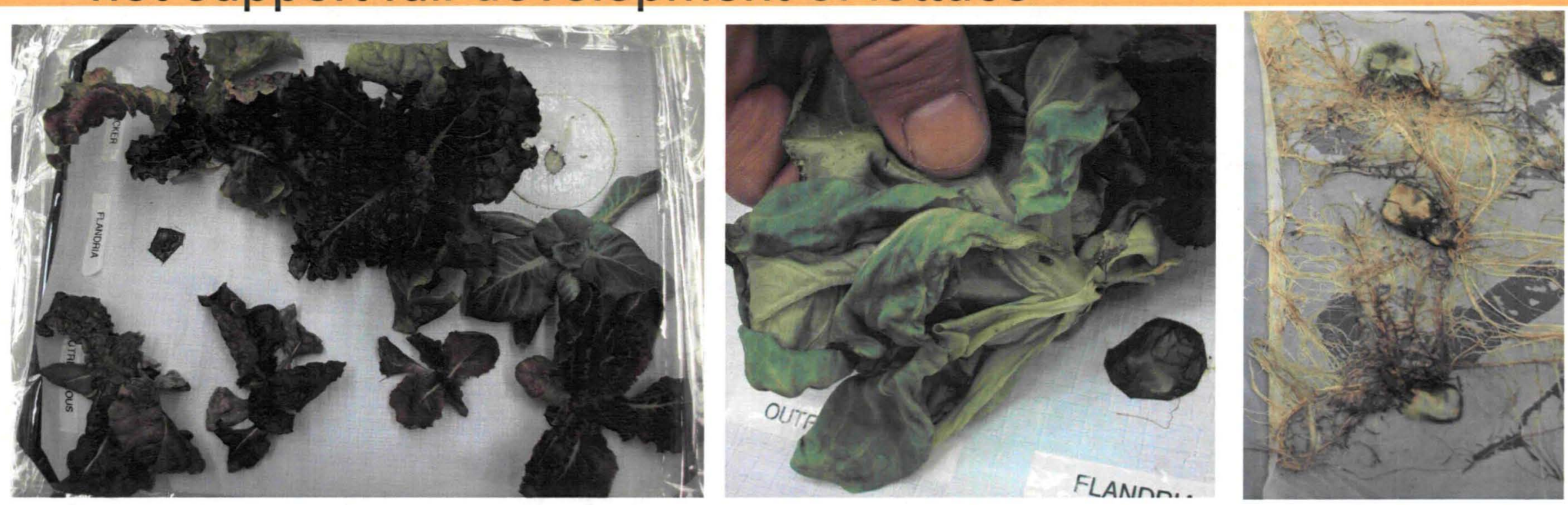

Good seed germination with placement on Nitex Initial root growth good, and did not penetrate into mat. Stunting was observed after 7-10 days and leaf tip necrosis appeared by 14 DAP.

Stem girdling, resulting in loss of the plant, was apparent by 18 days, which was accompanied by root necrosis. 


\section{OAIAA}

Concept 2: Seeding onto rooting media.

- Modification of approach previously used with VEGGIE.

- Two media, Oasis and Rockwool, were evaluated.

- Media were attached to Nitex with gum guar.

- Opaque covering added.

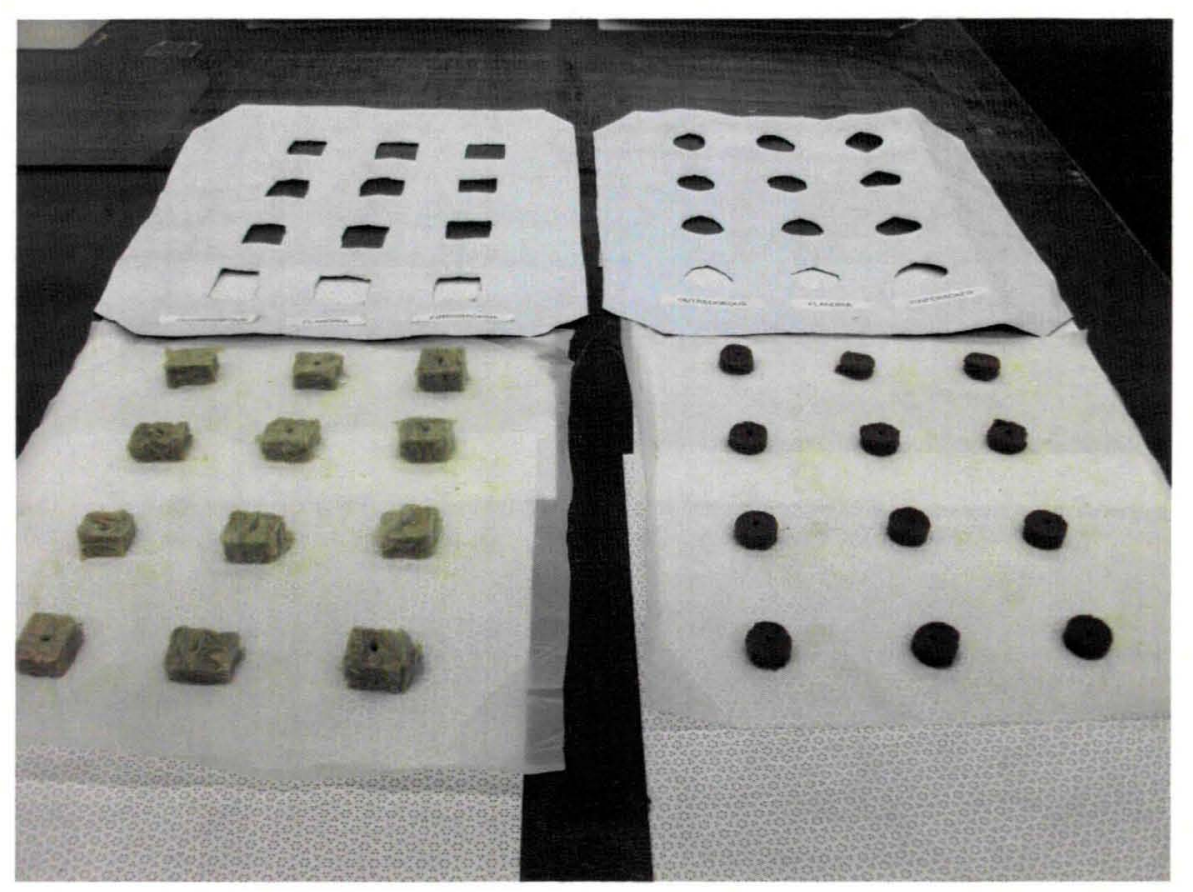




\section{Concept 2: Results}
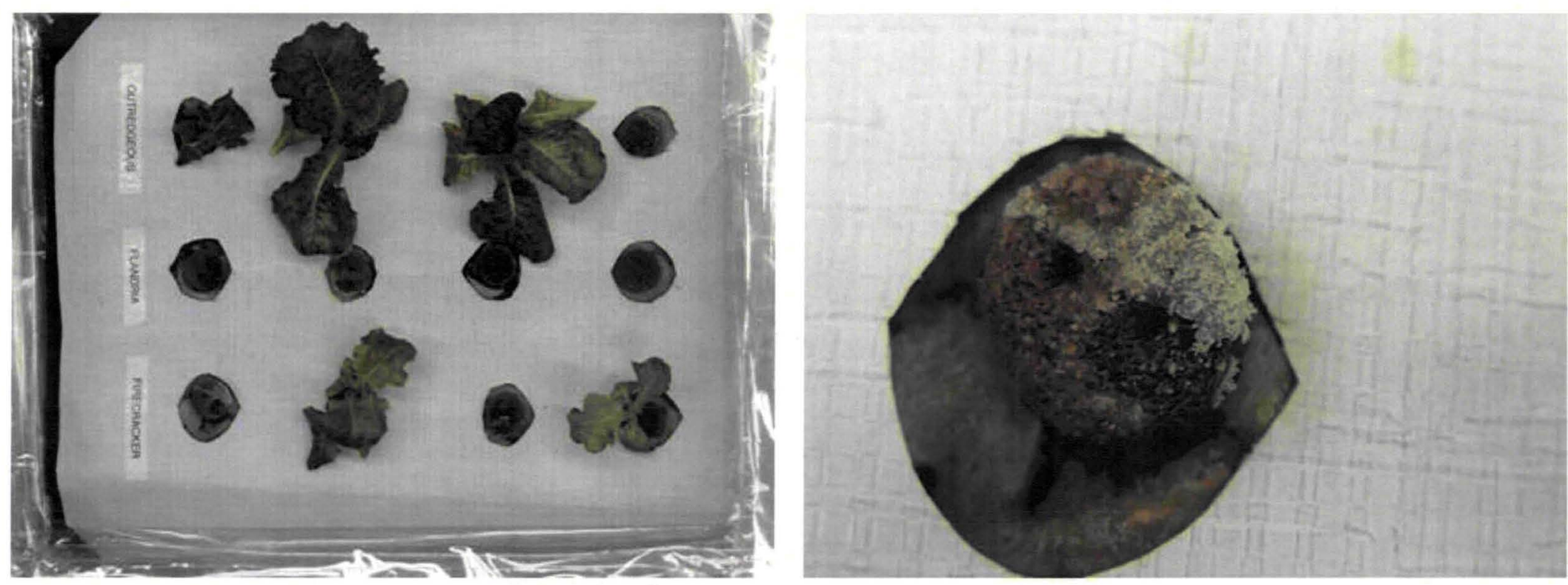

Red leaf cultivars, Outredgeous and Firecracker, established better than the green bibb cultivar Flandria on the Oasis plugs. However, they exhibited signs of severe stress. There was significant accumulation of salt on the surface of the Oasis plugs which prevented plant growth 

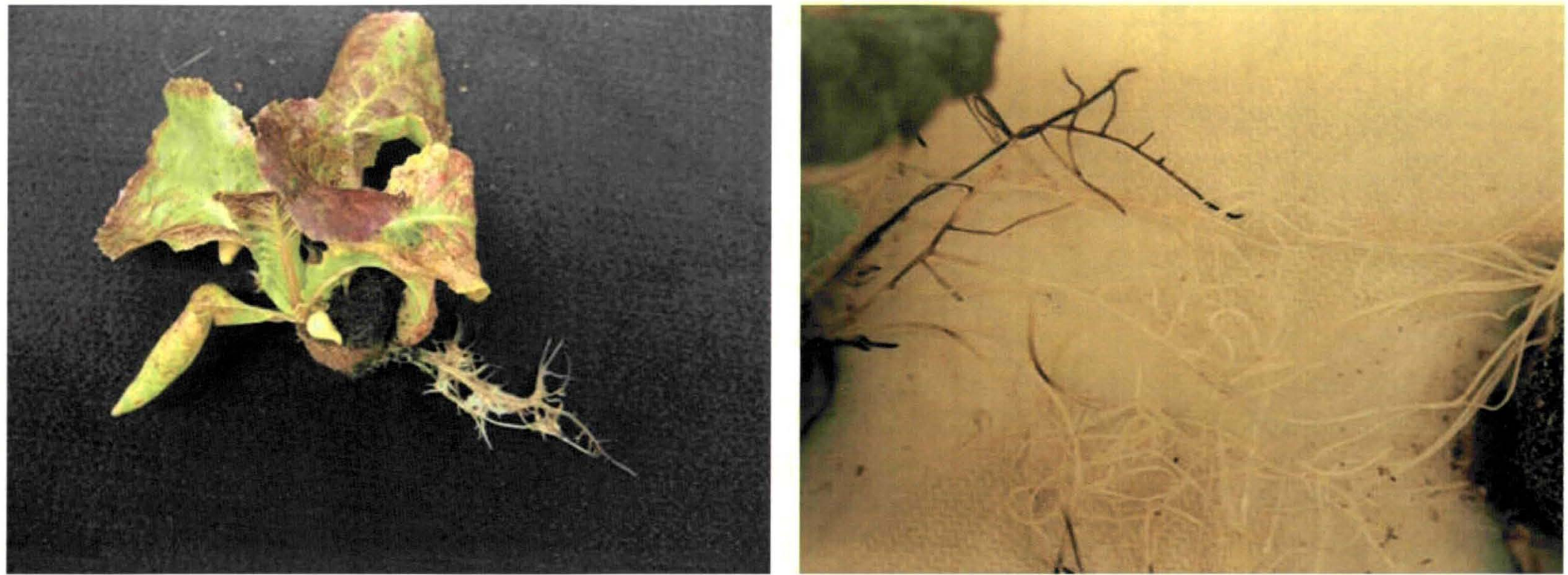

Lettuce cv. Firecracker (11 DAP) exhibits symptoms of salt toxicity on the leaves and roots. Note that the roots developed out from the Oasis plug and along the surface of the Nitex (. Roots that emerged from the Oasis plug exhibited several symptoms of distress, including tip browning and necrosis. 
Salt accumulation on surface of plugs was correlated with high VPD and surface/volume ratio's in VEGGIE

\begin{tabular}{lrr} 
Components & $\begin{array}{r}\text { VEGGIE } \\
\text { (Flight) }\end{array}$ & $\begin{array}{r}\text { BPSe } \\
\text { (Surface) }\end{array}$ \\
\hline Dimensions $(\mathrm{cm})$ & $2 \times 2 \times 2$ & $5 \times 5 \times 8$ \\
Volume $\left(\mathrm{cm}^{3}\right)$ & 8 & 200 \\
Exposed Surface $\mathrm{area}^{*}\left(\mathrm{~cm}^{2}\right)$ & 20 & 25 \\
Surface/Vol ratio $\left(\mathrm{cm}^{2} / \mathrm{cm}^{3}\right)$ & 2.5 & 0.125 \\
Temp $\left({ }^{\circ} \mathrm{C}\right)$ & 31 & 24 \\
RH $(\%)$ & 45 & 54 \\
VPD & 2,47 & 1,37
\end{tabular}

* Area exposed to atmosphere only. Surfaces protected by attachment to media and/or covered by pot are excluded 


\section{Concept 3: VEGGIE Rooting Pillow}

- A pillow is constructed of opaque material and the edges heat welded to provide a seal.

- A "window' is cut into the bottom of the pillow, and Nitex is heat welded to the plastic to provide a porous surface.

- A tube is placed into the pillow to allow initial wetting.

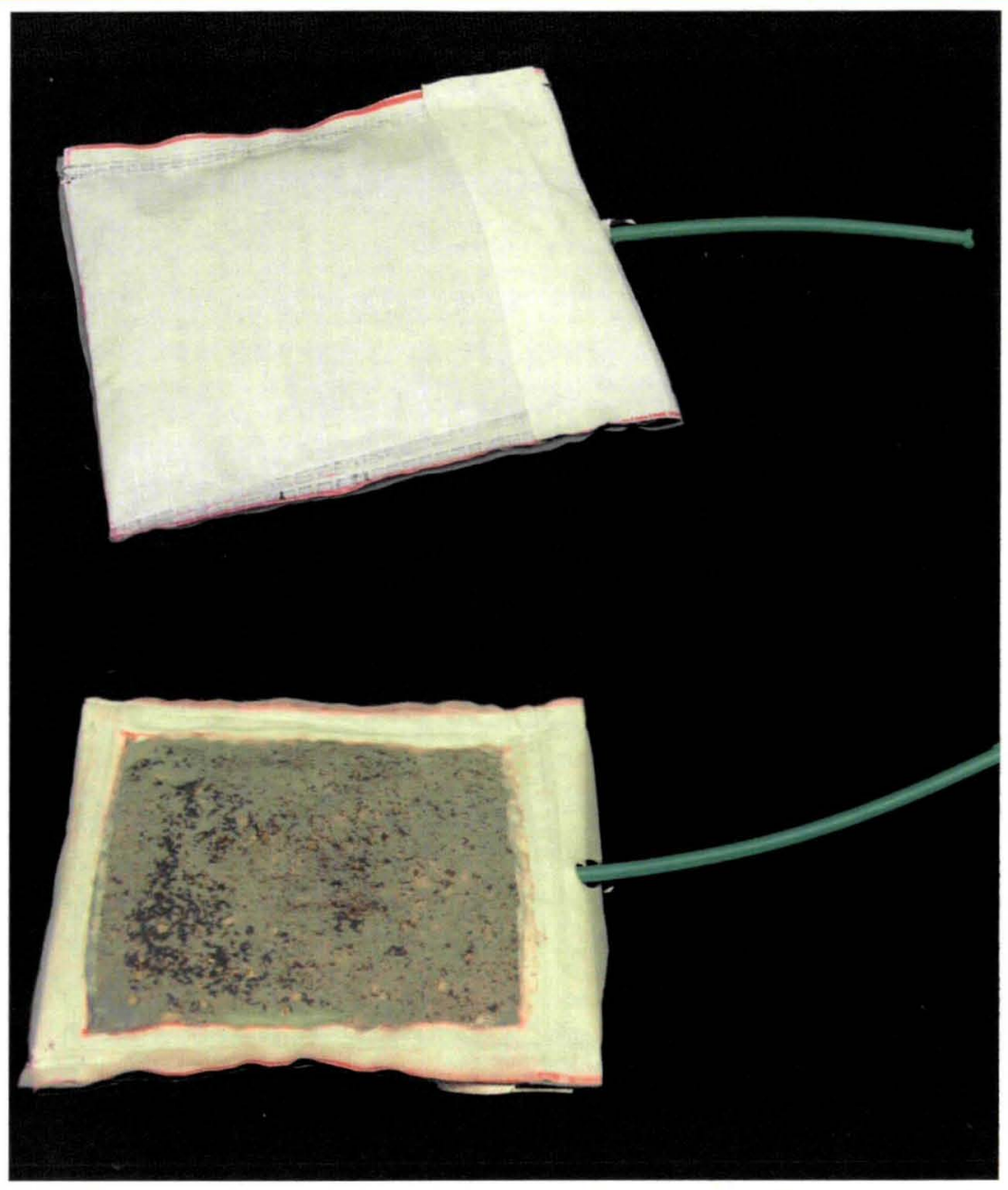


Concept 3: VEGGIE Rooting Pillow separated water and nutrient delivery systems

- Primary water supply is through the rooting mat contained within the rooting envelope.

- The watering tube was inserted into end of the pillow for initial watering only in order to overcome hysteresis of the media

- Nutrients provided by slow release fertilizer (Osmocote or Nutricote) incorporated into a rooting media placed into the pillow and sealed.
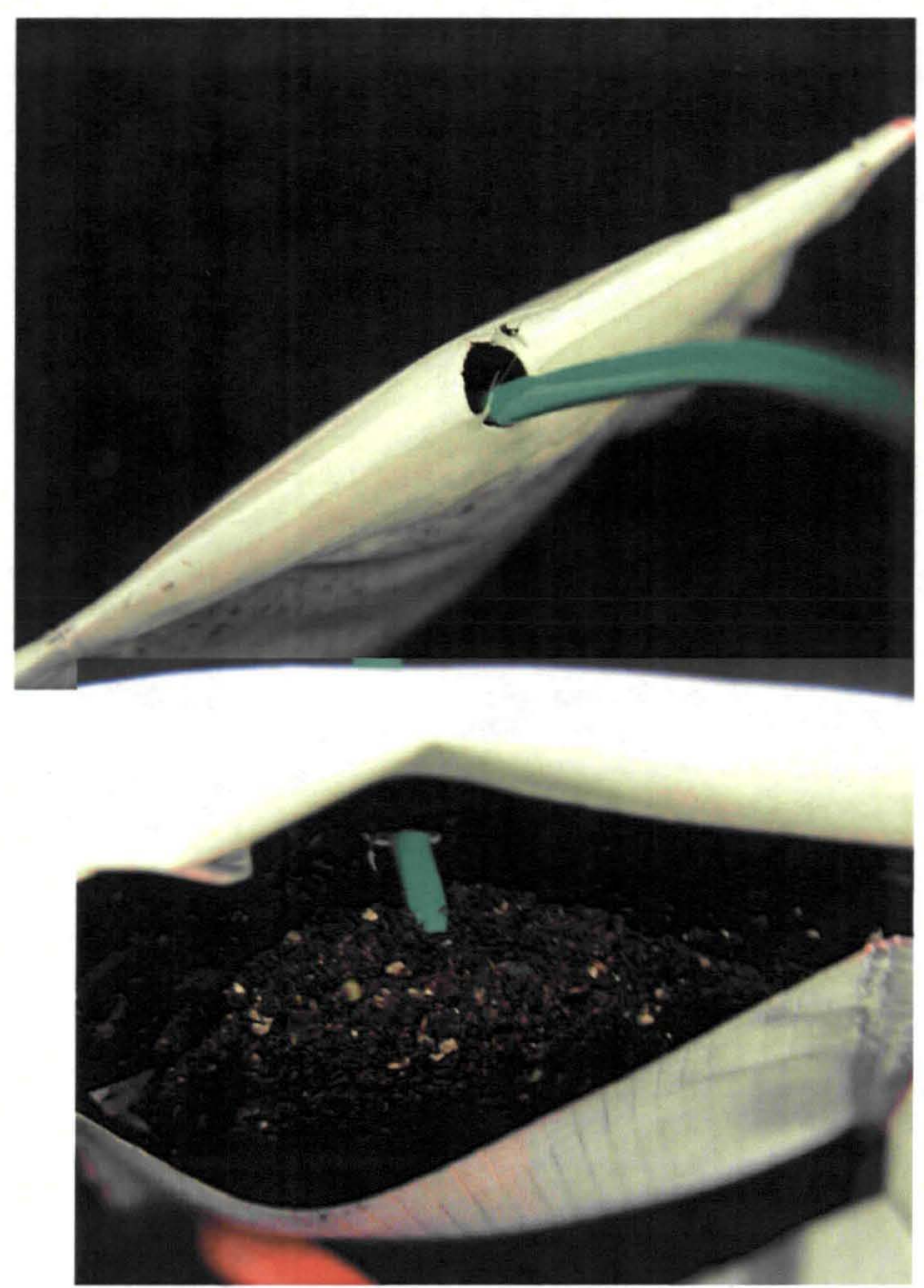


\section{OAIAA:}

Concept 3: Water is provided to rooting media through capillary action and driven by evapotranspiration rate.
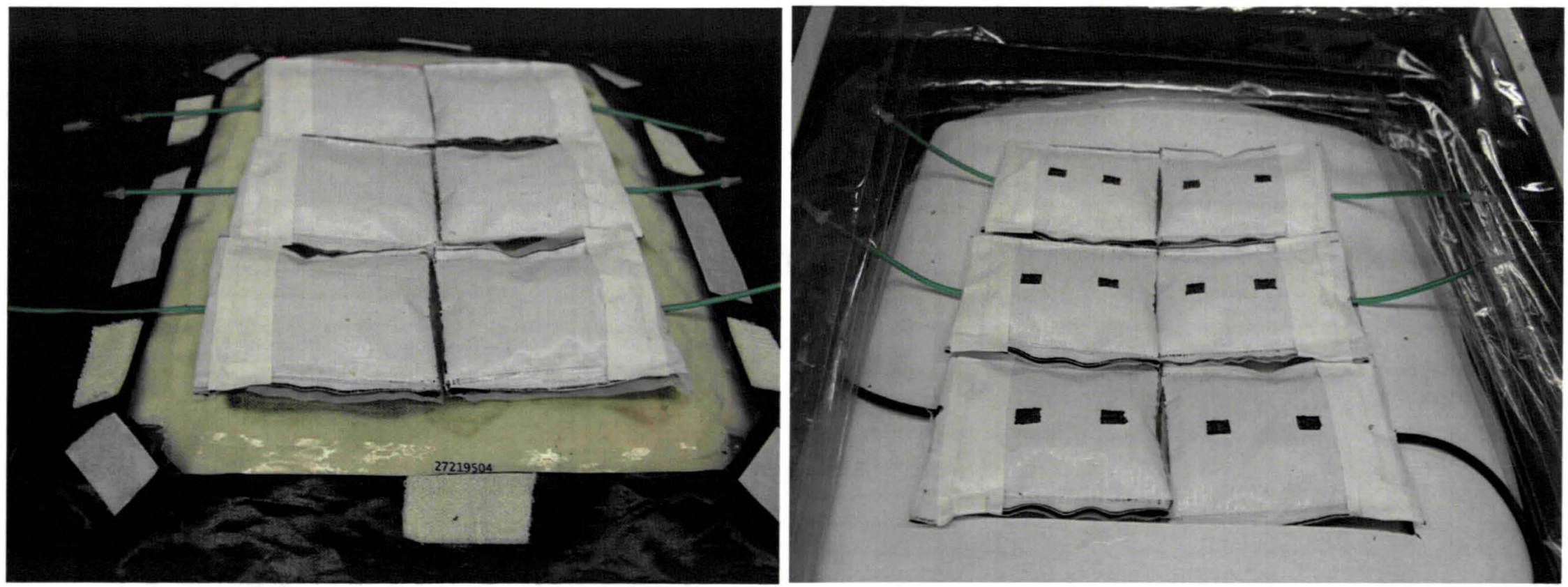

- Pillows are placed directly on the VEGGIE Nomex rooting mat, and exposed areas covered with opaque material to minimize algae growth. 
Concept 3: Plant growth surface is separated from the VEGGIE root mat with a hydrophilic barrier.

- Distilled water was maintained in the rooting reservoir, and very algae growth was minimal.

- There was excellent early growth of seedlings and roots were evenly distributed through the media

- All roots were contained

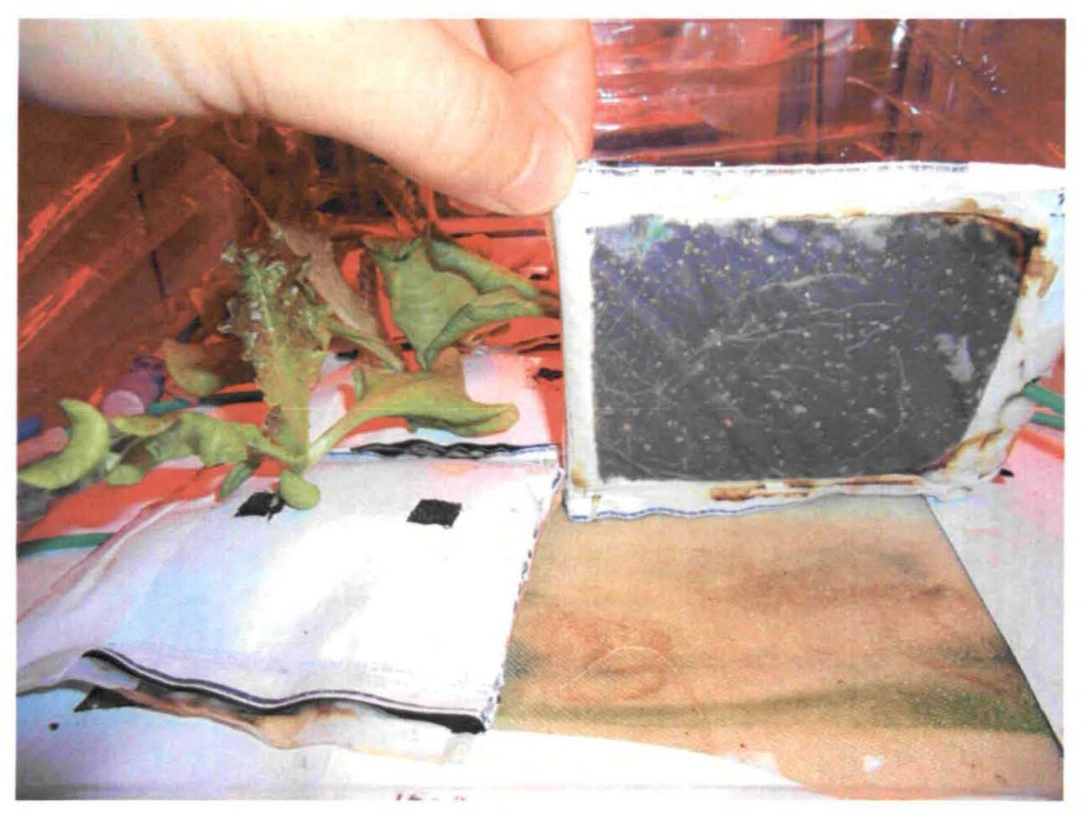
within the pillows. 


\section{OAIAA:}

Concept 3: Rooting Pillows supported growth for a full 28d life cycle of lettuce

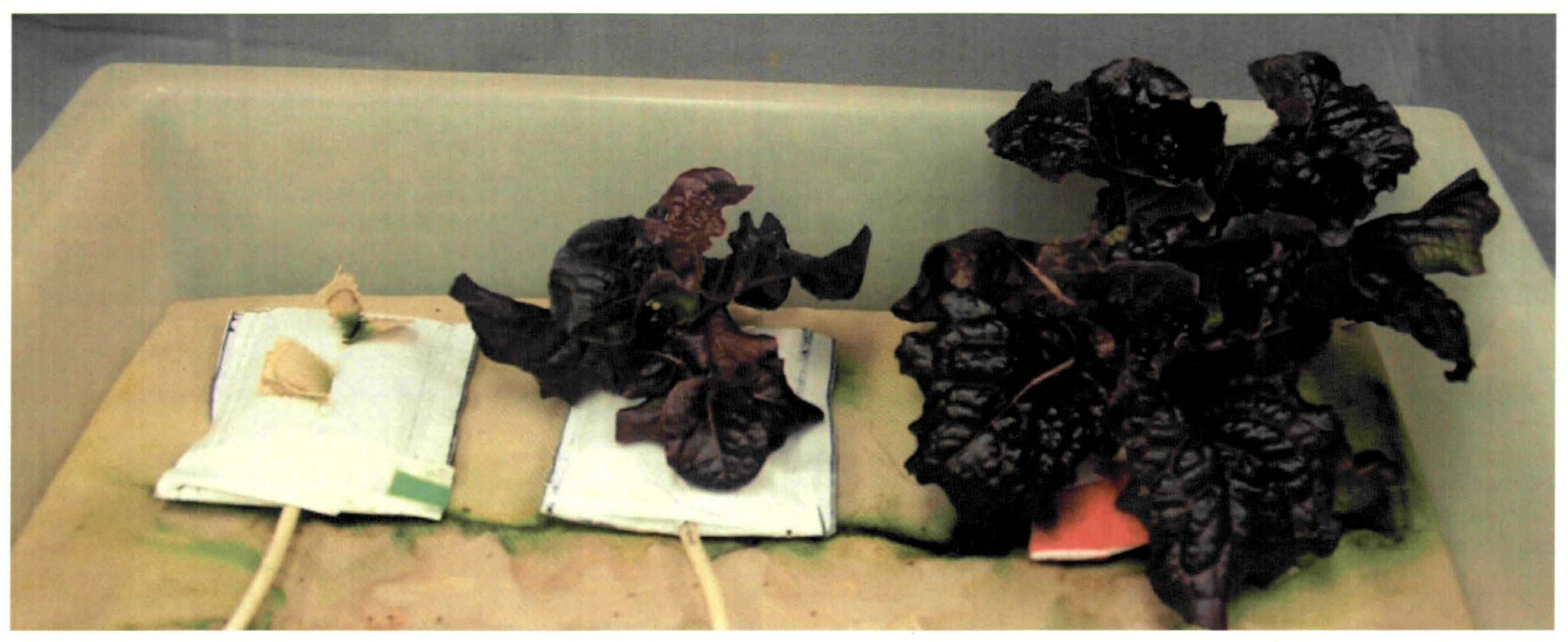

Outredgeous grown for 3,14 and 28 DAP in rooting pillows with peat/vermiculite mix and Nutricote as rooting media. 


\section{OAIAA:}

Concept 3: Rooting Pillows supported excellent lettuce growth for a complete 28 day life cycle.

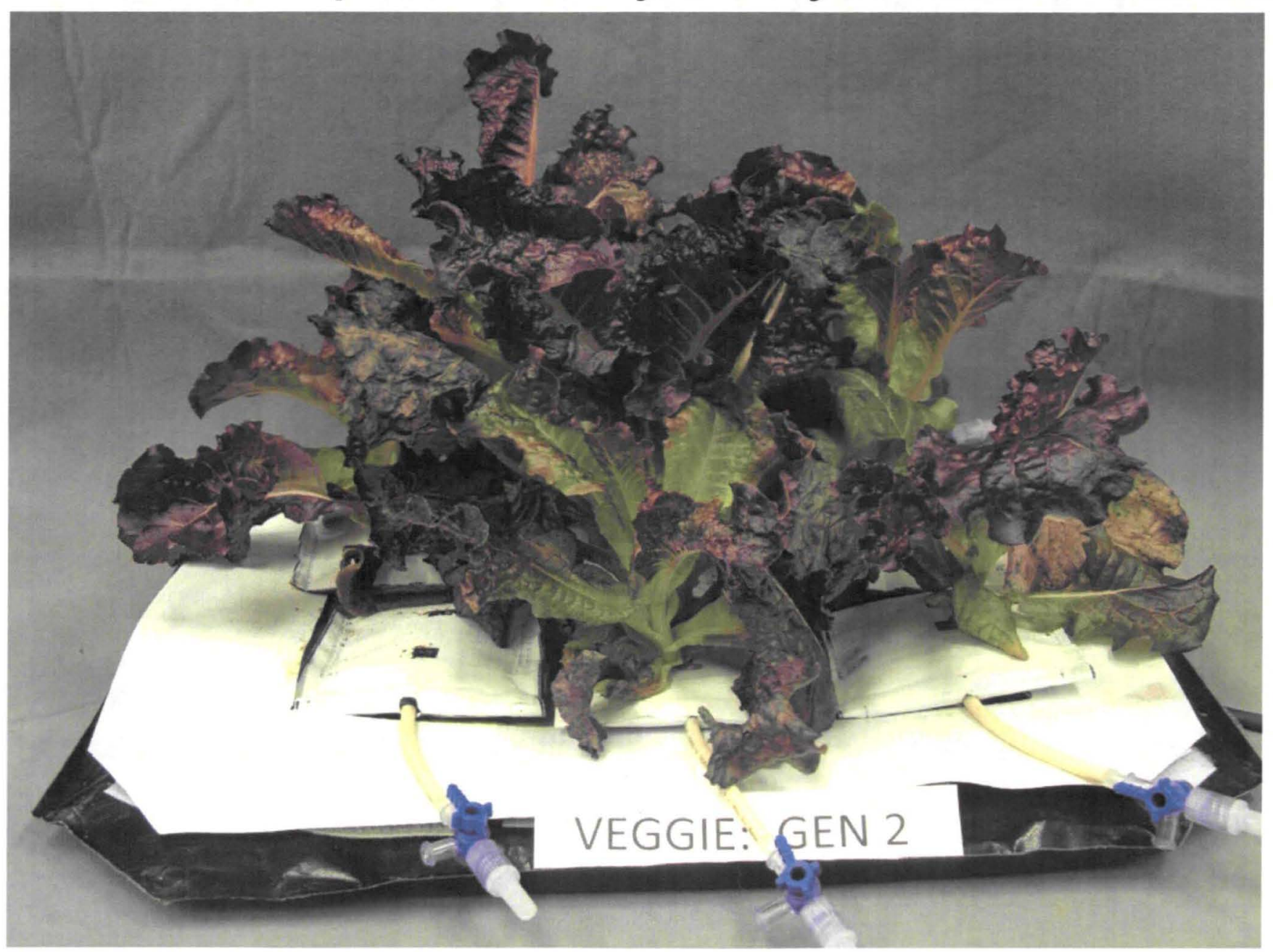




\section{OAIAA:}

Fresh mass of lettuce grown in rooting pillows was comparable to those grown in pots at same growth conditions.

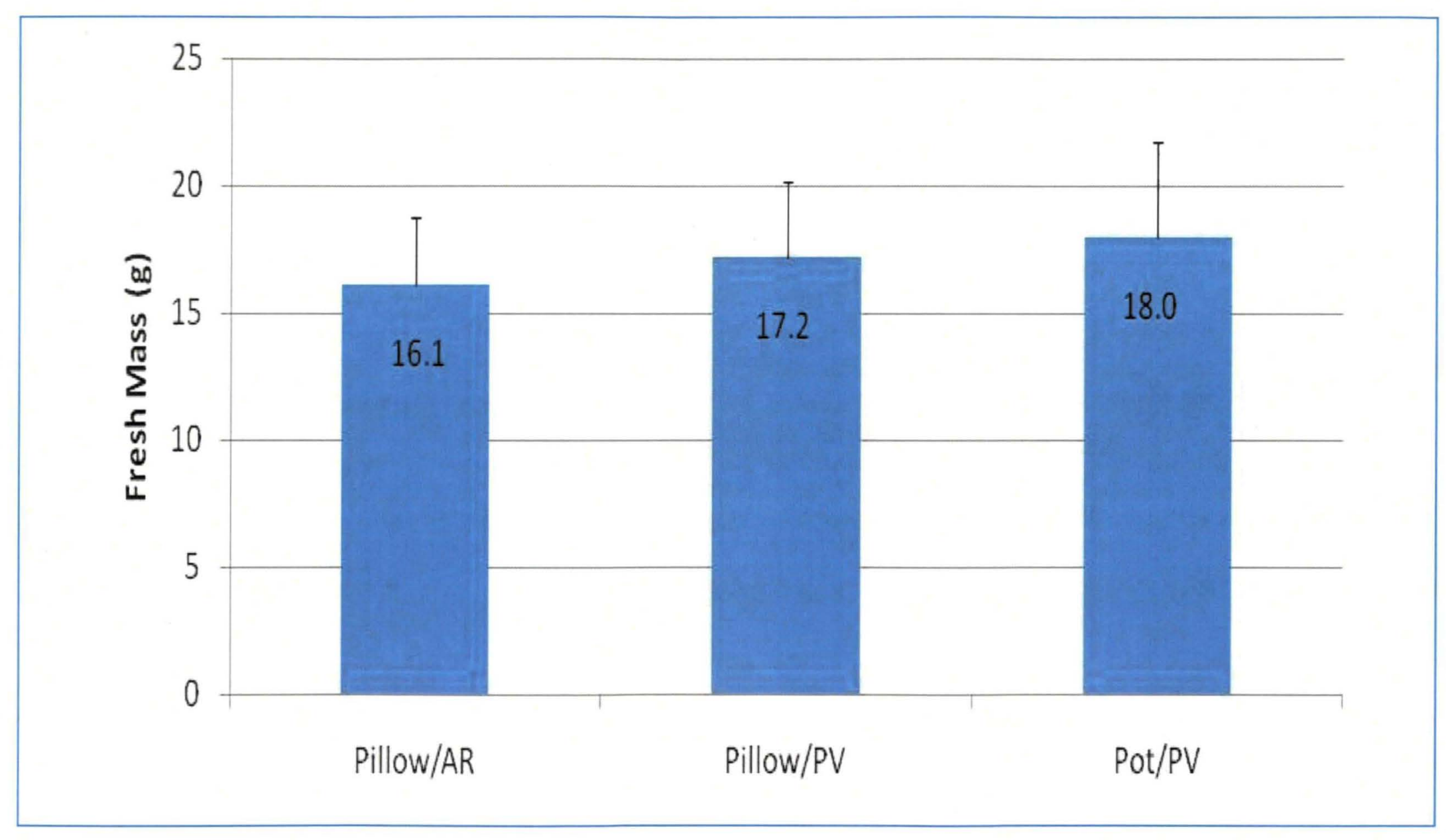

$A R=$ arcillite $P V=$ peat vermiculite mix Pot= surface configuration 


\section{Refinement of Rooting Pillows for flight applications.}
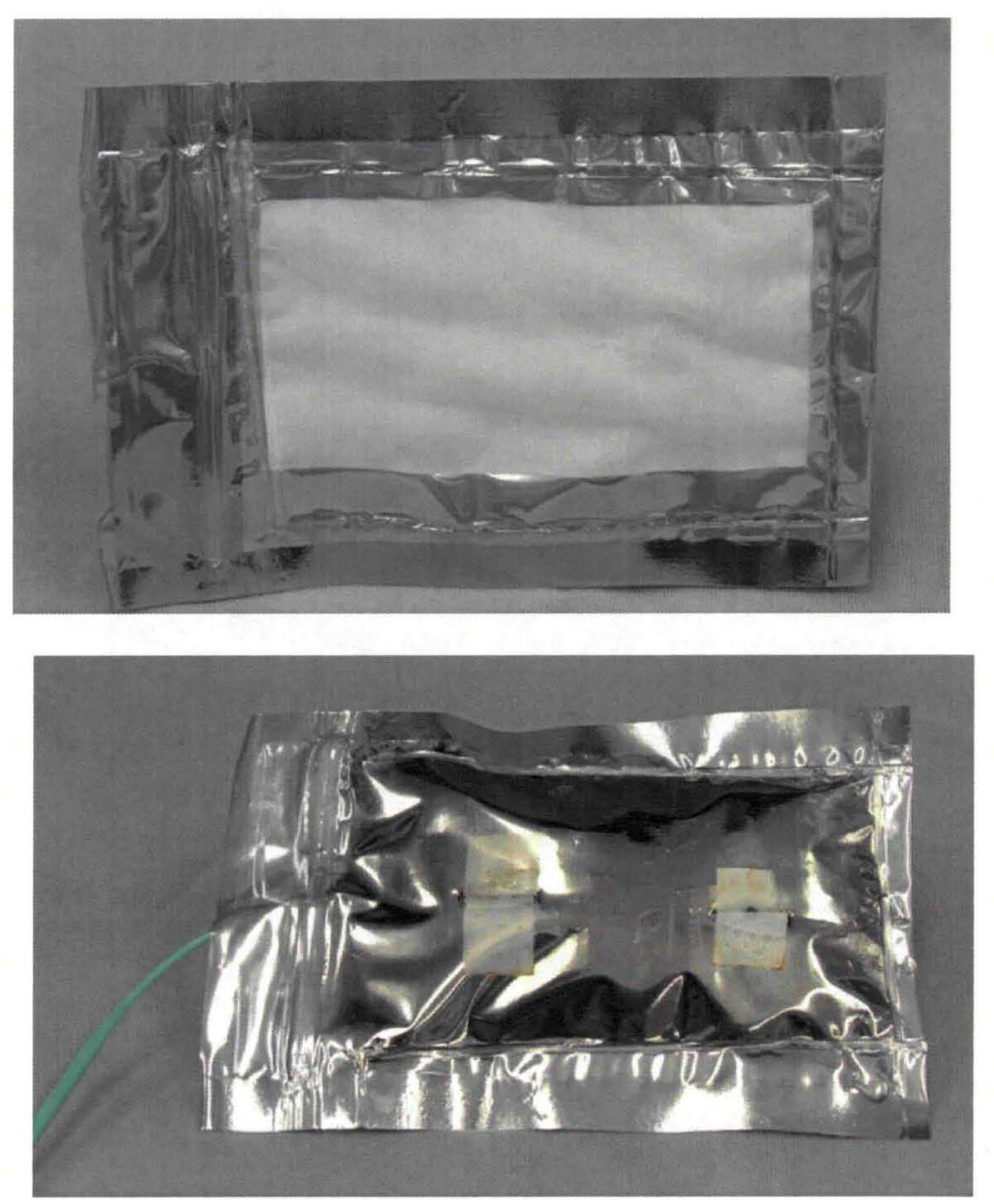

- $7.6 \mathrm{~cm} \times 17.7 \mathrm{~cm}$ Metallic static free zip lock bags (Polybag Suppliers, Charlotte, NC) were used a primary pillow.

- $6.3 \mathrm{~cm}$ x $10.2 \mathrm{~cm}$ Nitex window was heat welded onto the polybag to create the water-permeable Nitex barrier.

- Nitex wicks were inserted into narrow slits to retain the seeds and media.

- Water was provided through wicking from the VEGGIE rooting mat. 


\section{OAIAA:}

Concept of rooting pillows is effect approach for plant growth under microgravity conditions.

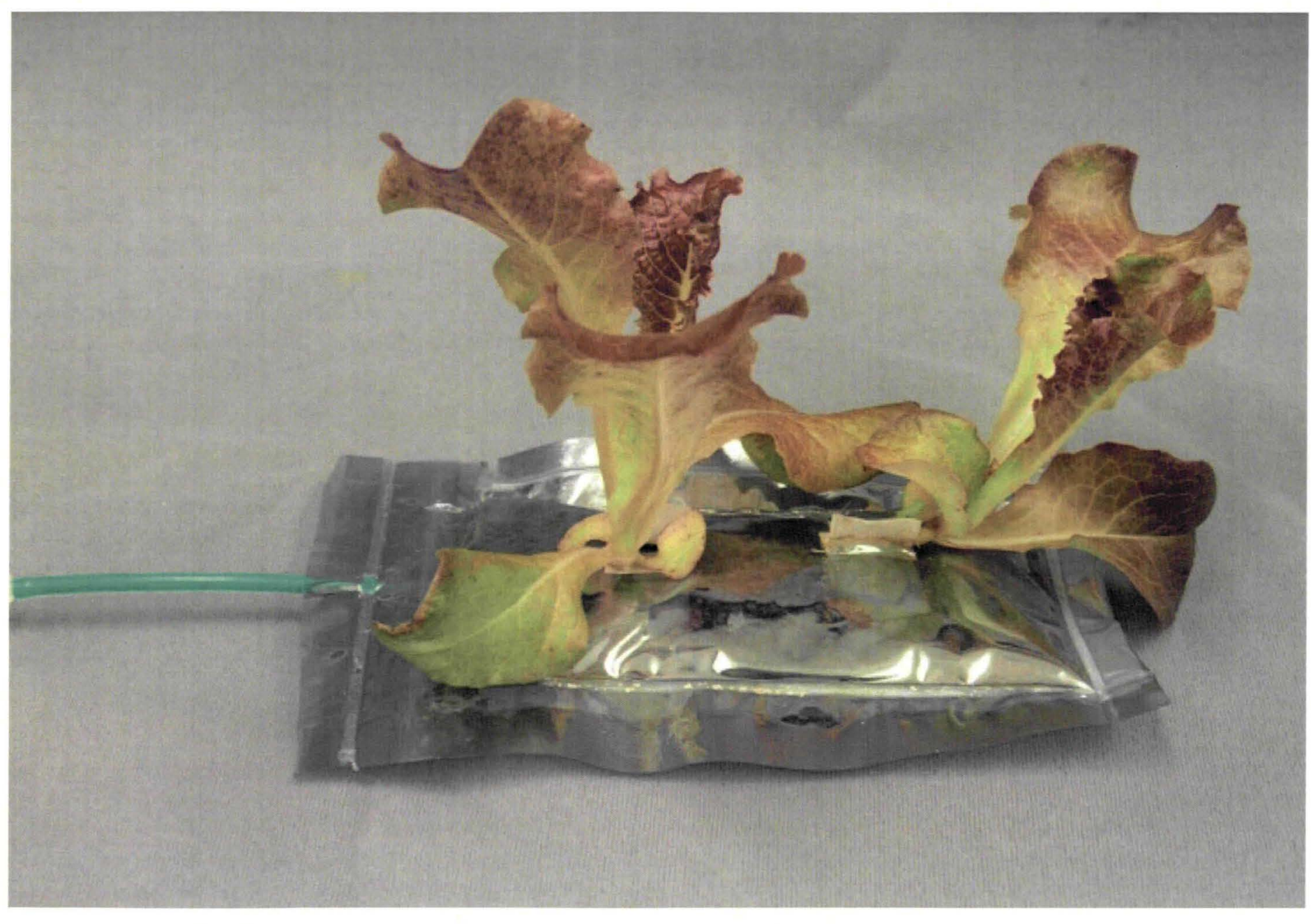



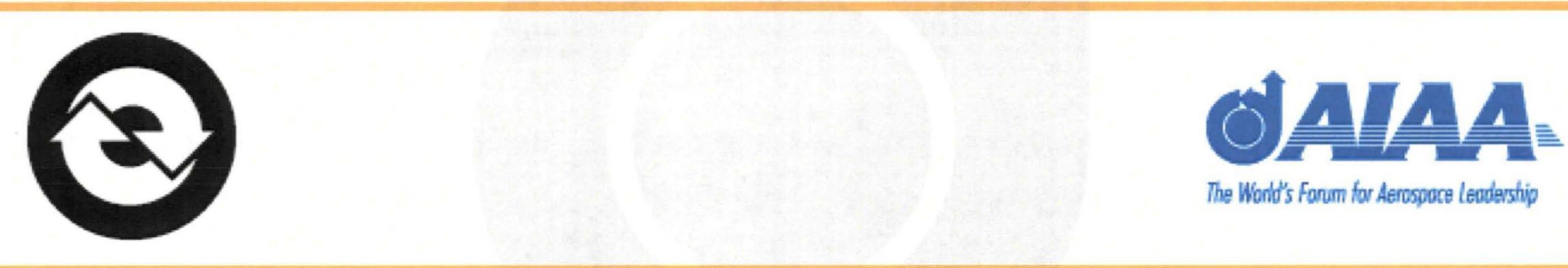

Thanks to Kennedy Space Center IPP funding, and to Larry Koss for his help throughout the project. 